\title{
Estrogen receptor-a signaling in post-natal mammary development and breast cancers
}

\author{
Mariam Rusidzé ${ }^{1}$ - Marine Adlanmérini ${ }^{1}$ - Elodie Chantalat ${ }^{1}$ - I. Raymond-Letron ${ }^{2} \cdot$ Surya Cayre $^{3}$. \\ Jean-François Arnal ${ }^{1} \cdot$ Marie-Ange Deugnier $^{3} \cdot$ Françoise Lenfant $^{1}{ }^{10}$
}

Received: 25 January 2021 / Revised: 12 May 2021 / Accepted: 19 May 2021 / Published online: 22 June 2021

(c) The Author(s) 2021

\begin{abstract}
$17 \beta$-estradiol controls post-natal mammary gland development and exerts its effects through Estrogen Receptor ER $\alpha$, a member of the nuclear receptor family. ER $\alpha$ is also critical for breast cancer progression and remains a central therapeutic target for hormone-dependent breast cancers. In this review, we summarize the current understanding of the complex ER $\alpha$ signaling pathways that involve either classical nuclear "genomic" or membrane "non-genomic" actions and regulate in concert with other hormones the different stages of mammary development. We describe the cellular and molecular features of the luminal cell lineage expressing ER $\alpha$ and provide an overview of the transgenic mouse models impacting ER $\alpha$ signaling, highlighting the pivotal role of ER $\alpha$ in mammary gland morphogenesis and function and its implication in the tumorigenic processes. Finally, we describe the main features of the ER $\alpha$-positive luminal breast cancers and their modeling in mice.
\end{abstract}

Keywords Mammary gland $\cdot 17 \beta$-estradiol $\cdot$ ER $\alpha$-positive luminal cells $\cdot$ Lineage specification $\cdot$ Stem cells

\section{Introduction}

The mammary gland is an exocrine gland of ectodermal origin whose primary function is to produce milk for the nourishment of offspring. In humans as in most mammals, mammary morphogenesis is initiated during the embryonic period but the most important part of mammary development and remodeling occurs after birth, throughout puberty, pregnancy, lactation and involution [1-6]. Despite some differences, the human and mouse mammary epithelium shares strong similarities in developmental processes, cellular

Marine Adlanmérini and Elodie Chantalat have contributed equally.

Françoise Lenfant

francoise.lenfant@inserm.fr

1 INSERM U1297, Institut Des Maladies Métaboliques et Cardiovasculaires, Université de Toulouse - UPS, CHU, Toulouse, France

2 LabHPEC et Institut RESTORE, Université de Toulouse, CNRS U-5070, EFS, ENVT, Inserm U1301, Toulouse, France

3 Department of Cell Biology and Cancer, Institut Curie, PSL Research University, Sorbonne University, CNRS UMR144 Paris, France organization and signaling molecules $[4,7]$. Mouse models are, therefore, widely used to decipher the molecular mechanisms controlling the development and homeostasis of the mammary gland, and analyze their deregulation upon tumorigenic processes.

The post-natal development of the mammary gland and its function are controlled by a hormonal network that mainly comprises estrogens, progesterone, prolactin, growth hormone $(\mathrm{GH})$ and oxytocin [3, 8]. Prolactin, GH and oxytocin are peptide hormones of pituitary origin, whereas estrogens and progesterone are steroid hormones primarily produced by ovaries during reproductive life. Pioneering works showing that ovariectomized and ER $\alpha$-deficient mice were unable to develop mammary gland at puberty have indicated that signaling through estrogens is crucial for the post-natal mammary development [9-12]. In addition, ER $\alpha$ is routinely used as a diagnosis marker supporting the molecular classification of breast cancers [13-15] and remains an essential therapeutic target for hormone-dependent breast cancers, in particular through administration of tamoxifen (TAM) and/ or aromatase inhibitors (AI), that both are very efficient in reducing the risk of cancer recurrence [16-18].

As member of the nuclear receptor family, ER $\alpha$ has a well-established transcription factor activity and controls the expression a large spectrum of target genes [19, 20]. 
However, estrogens and ER $\alpha$ can also act at the cell membrane level to induce non-genomic events [21, 22]. The recent development of new transgenic mouse models and omics-based analyses has allowed to better characterize the ERo-positive luminal cell lineage and to further dissect the complex signaling events triggered by estrogens in the mammary epithelium. Here, we review the current understanding of the mechanisms of ER $\alpha$ actions, derived from different studies on mammary development, stem cell function and tumorigenesis.

\section{ERa and its modes of action}

In humans and rodents, two distinct estrogen receptors, ER $\alpha$ and ER $\beta$, have been identified. They show large sequence homology and similar binding affinity for $17 \beta$-estradiol (E2), the predominant form of circulating estrogens [19, 23]. Esr 1 (ESR1 in human) encoding ER $\alpha$ was first identified in 1986 $[24,25]$ and located on a different chromosome than Esr2 coding for ER $\beta$, identified later in 1996 [26]. ER $\alpha$ is believed to be the ancestral steroid receptor originating 400-500 million years ago [27] and its complex modes of action and gene organization remain abundantly studied [28]. In vivo, perturbation of ER $\alpha$ signaling has a major impact on mammary development $[11,12]$, whereas ER $\beta$ loss does not result in a deleterious mammary phenotype and impaired function $[29,30]$.

ESR1 gene spans over $300 \mathrm{~kb}$ and consists of nine coding exons and seven introns (Fig. 1). The first eight exons encode the major full-length $66 \mathrm{kDa}$ isoform of $\mathrm{ER} \alpha$ [31]. The promoter region (over $150 \mathrm{~kb}$ ) contains several promoter sequences named $\mathrm{A}$ to $\mathrm{T}$ that drives its specific expression in target tissues [32, 33]. ESRI gene expression is tightly regulated by multiple regulatory elements, including transcription factors, chromatin environment, autocrine, paracrine and endocrine secreted factors, and multiple environment factors (cell-cell and cell-matrix interactions, mechanical forces) [34]. In addition, the 3'UTR region of ER $\alpha$ contains several regulatory elements specific for miRNAs, such as miR18a, miR22, miR206 and miR221/22, that control ER $\alpha$ stability or translocation [35].

$\mathrm{ER} \alpha$ is composed of six structural domains namely A to $\mathrm{F}$, including two binding domains, one to DNA (DBD, C domain) and the other to ligand (LBD, E domain) [19, 21]. It also includes a ligand-independent (AF1) and a liganddependent (AF-2) subdomain, mapping to the $\mathrm{A} / \mathrm{B}$ and $\mathrm{E}$ domains, respectively [36, 37] (Fig. 1). The AF-1 transactivation domain is mainly ligand independent, its stimulation relying on the phosphorylation of serine 104/106, 118 or 167 by kinases activated downstream of growth factors such as EGF (Epidermal Growth Factor), IGF-1 (Insulin-like Growth Factor-1), or TGF $\alpha$ (Tumor Growth Factor) [38-41]. However, AF-1 can also be modified in response to E2 and further stabilized following phosphorylation on serine 118 [42-44]. The A domain interacts with the C-terminal domain to allow repression in absence of ligand [45]. The D domain is a hinge region that provides flexibility between the DBD and the LBD (E/ F) domains. The mutation of this D region affects the synergy between the AF-1 and AF-2 functions of $\mathrm{ER} \alpha$ [46]. $\mathrm{AF} 1$ and $\mathrm{AF} 2$ display distinct activation functions that are specifically involved in the recruitment of cofactors. These coregulators are not only proteins that link the receptor and the transcription machinery but rather have enzymatic activities that induce chromatin modification and remodeling, and control initiation of transcription [47-49]. Among the coregulators that bind to the AF-2 domain exposed following E2 binding, there are members of the p160 family that includes three analogous factors SRC-1, SRC-2 and SRC-3 (Steroid Receptor Coactivator, part of histone deacetylase) $[50,51]$. Other well-known cofactors comprise CBP/p300 and MED1. Interestingly, p160 proteins also interact with the $\mathrm{NH} 2$-terminal domain of $\mathrm{ER} \alpha$, in particular the AF1 domain, and p300 allows a functional synergy between AF1 and AF2 [40, 52]. This was confirmed by the recent quaternary structure of an active ER $\alpha$-coregulator
Fig. 1 Structure of the ESR1 gene and the different isoforms of ER $\alpha$. On the top, the coding exons are annotated following the nomenclature published in [32]. Alternative splicing that generates the shorter ER $\alpha 46$ and $\mathrm{ER} \alpha 36$ isoforms are indicated using solid lines
A

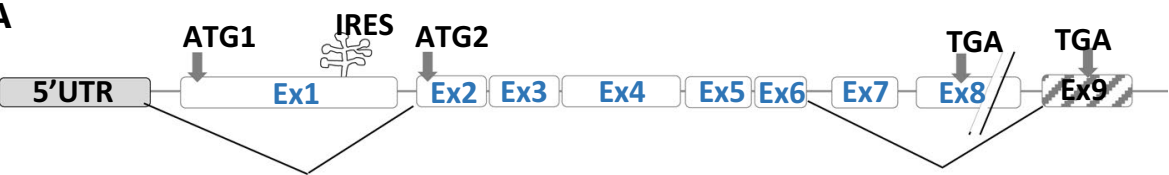

B

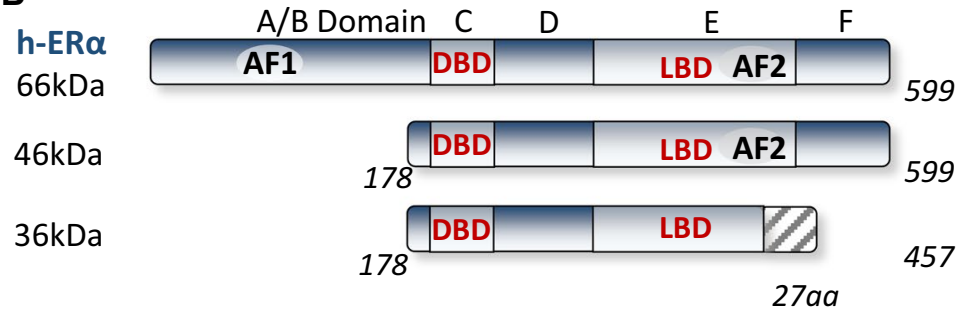


complex on DNA identified using cryoelectron microscopy [53]. Moreover, ER $\alpha$ also interacts with some corepressors, such as the repressor of estrogen receptor activity (REA) repressor which binds on the LBD domain in a liganddependent manner [54] or RIP140 (receptor interacting protein) through a direct competition with SCR-1 [55].

\section{Natural isoforms of ERa}

In addition to the "classic" full-length isoform of $\mathrm{ER} \alpha(\mathrm{ER} \alpha-$ $66 \mathrm{kDa}$ ) which contains the two AF-1 and AF-2 activation functions, there is a shorter $46 \mathrm{kDa}$ isoform lacking the first 173 amino acids and, therefore, the AF-1 function (Fig. 1). Although the prominent, if any, mechanisms accounting for the expression of the ER $\alpha 46$ isoform still remain to be clarified, three possible processes of generation were reported: $(i)$ an alternative splicing that generated a mRNA deficient in the nucleotide sequence corresponding to exon 1 encoding the A/B domain generation [56]; (ii) proteolysis [57, 58]; and (iii) initiation of translation at a downstream ATG which encodes methionine 174 in the human ER $\alpha 66$ by an IRES (Internal Ribosome Entry Site) located within the full-length mRNA [59]. A recent study showed that the expression of ER $\alpha 46$ is due to the action of the oncoprotein HMGA1a (High Mobility Group A protein1a) that regulates the alternative splicing of ESR1 in MCF7 breast cancer cells [60]. Overexpression of ER $\alpha 46$ in proliferating MCF7 cells provokes a cell cycle arrest in G0/G1 phases and inhibits the ER $\alpha 66$-mediated estrogenic induction of all AF-1-sensitive reporters: c-fos and cyclin D1 as well as estrogen-responsive element-driven reporters $[56,61]$. The role of the AF1-deficient ER $\alpha 46$ isoform has also been questioned in vivo using a "knock in" strategy. These mice (named $E R \alpha A F-1^{0}$ ) only express a short $49 \mathrm{kDa}$ isoform that lacks 441 nucleotides from exon 1 and is functionally similar to ER $\alpha 46$ [62]. The females are sterile, with uterine atrophy while they conserved several vasculoprotective actions of E2 [62-64]. Studies on mammary gland development are reported later in chapter 4.1 .

Western blot with antibodies directed against the C-terminal domain is the unique procedure to detect the ER $\alpha 46$ isoform since $\mathrm{ER} \alpha 46$ and $\mathrm{ER} \alpha 66$ share identical aminoacid sequences that cannot be distinguish by immunohistochemistry. Although the ER $\alpha 46$ isoform has not been studied extensively, it was found expressed in various cell types such as vascular endothelial cells and macrophages [65-68]. ER $\alpha 46$ is also expressed in breast cancer cells including tamoxifenresistant cells [69] and in more than 70\% of human breast tumors with highly variable expression levels, sometimes even more abundant than the ER $\alpha 66$ protein [70]. Importantly, higher amounts of ER $\alpha 46$ proteins were associated with highly differentiated tumors of lower grade and smaller size [70].

In 2005, another shorter $36 \mathrm{kDa}$ isoform of $\mathrm{ER} \alpha$ was identified from a human endometrium cDNA library [71]. This ER $\alpha 36$ isoform is transcribed from an alternative promoter located in the first intron of the ESRI gene and is encoded by exons 1, 2-6, and 9 (Fig. 1). ER $\alpha-36$ thus lacks the transactivation functions AF-1 and AF-2 but retains the DNA-binding domain of ER $\alpha 66$ and its partial dimerization and ligand-binding domains. It also contains a unique 27 amino acids at the C-terminus that replaced the last 138 aminoacids encoded by exons 7 et 8 and can be detected by specific antibodies. ER $\alpha 36$ contains three potential myristoylation sites which are conserved in the full-length ER $\alpha 66$. These are residues 25-30 (GVWSCE), 76-81 (GMMKGG) and 171-176 (ELLTNL) [71]. Myristoylation being a posttranslational modification allowing anchoring to the plasma membrane, ER $\alpha-36$ was suggested to be mainly localized at the plasma membrane where it could relay rapid estrogen signaling and inhibit the transcriptional activity of ER $\alpha$ $66 \mathrm{kDa}$, probably by competition at DNA-binding sites [71, 72]. The ER $\alpha 36$ receptor is not expressed in mice. However, it was found largely expressed in both ER $\alpha$-positive and $\mathrm{ER} \alpha$-negative breast cancers, at a proportion that varies between 40 and 50\% according to cohort studies [73-75]. ER $\alpha 36$ is mainly described in the literature to be involved in the acquired resistance to anti-estrogen drugs, such as tamoxifen and in the progression of mammary tumors in response to chemotherapy [76].

\section{Complexity of actions of ERa signaling}

$\mathrm{ER} \alpha$ activation is a complex process involving many signaling pathways that trigger either classical nuclear "genomic" or membrane "non-genomic" actions (Fig. 2).

\section{The nuclear actions of ERa}

As a member of the nuclear receptor family, ER $\alpha$ mainly functions as a ligand-activated transcription factor through different mechanisms (Fig. 2). Estrogen binding to the LBD induces dissociation from the Hsp90/Hsp70-multi-protein chaperone machinery, receptor dimerization and nuclear entry. Crystal structure revealed that the LBD has 12 alpha helices and E2-binding repositionnes helix 12, such that activation function AF-2 is exposed, allowing interactions with coregulators [77]. ER $\alpha$ is then stabilized in its active state and binds directly to specific DNA sites to estrogenresponse elements (ERE $=5$ 'GGTCAnnnTGACC3' palindromic sequences) [78].

About 25\% of estrogen-regulated genes lack complete ERE sequences in their promoter regions [79]. Moreover, $\mathrm{ER} \alpha$ can bind to DNA by indirect tethering to other 


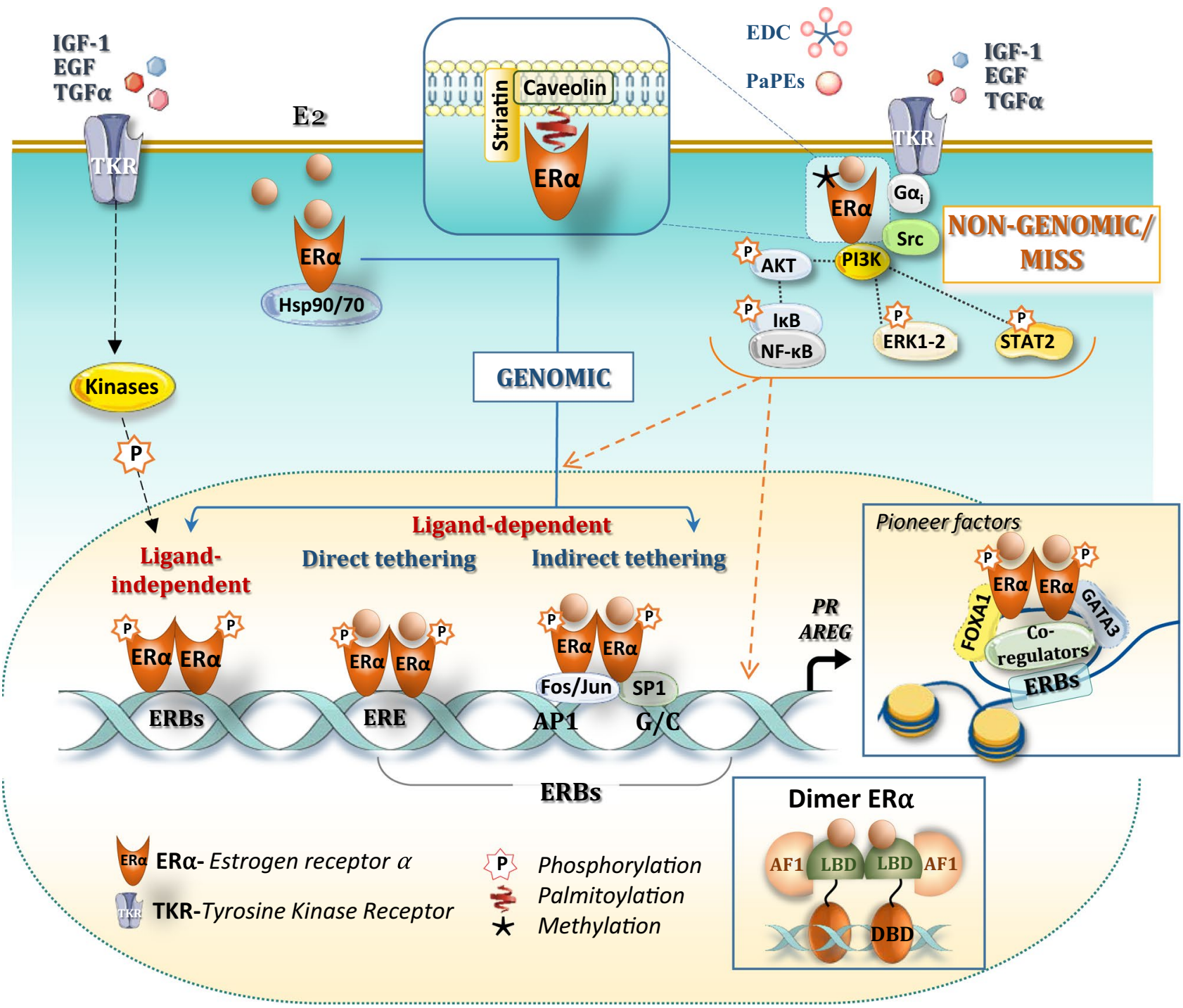

Fig. 2 Estrogen receptor $\mathrm{ER} \alpha$ signaling. Classic $\mathrm{ER} \alpha$ signaling leads to genomic actions through ligand-receptor binding, leading to dimerization of $\mathrm{ER} \alpha$ that binds directly to specific DNA sites (called estrogen response elements, ERE) that activate transcription. ER $\alpha$ can also bind by indirect tethering to other transcription factors, such as AP1 or SP1 (blue line). The ER $\alpha$ can also be activated in a ligandindependent manner through downstream events of receptor tyrosine kinases (RTKs) activated by growth factors in the mammary gland, such as IGF-1, EGF (blue dotted line, in particular through phosphorylation of serine residues in the AF-1 domain). Induction of transcriptional response depends on the chromatin remodeling, induced by pioneer factors such as FoxA1 and GATA-3 in the mammary gland, and is modulated by the specific recruitment of coregulators.

transcription factors such as the Stimulating protein 1 (SP1) on sites rich in GC, the jun/c-fos proteins which form a dimeric complex binding to "Activator Protein 1" (AP-1) sites [80] and Nuclear factor- $\kappa \beta$ (NF- $\kappa \beta)$. Genomewide analysis of ER $\alpha$ DNA-binding sites has identified not only rigorously dissociate the genomic and, but also
Non-genomic, membrane-initiated steroid signaling (MISS) actions involve a small pool of ER $\alpha$ located on the extracellular compartment or close to the membrane, at least in part through direct interaction with caveolin-1 in response to post-translational modifications such as palmitoylation. Transient methylation of arginine 260 has also been observed to induce $\mathrm{ER} \alpha$ interaction with the $\mathrm{p} 85$ subunit of PI3K and Src, Upon E2 binding, these non-genomic activations activate the subsequent interaction of $\mathrm{ER} \alpha$ with protein kinases ( $\mathrm{Src}$ and PI3K), G-coupled protein I, leading to activation of signaling cascades (Akt, ERK1/2) and further shuttle of these phosphorylated transcription factors in the nucleus. These non-genomic signaling pathways are rapidly activated and further induce genomic activations (orange dotted line)

PITX1 whose binding motif was found present in $28 \%$ of genome-wide ER $\alpha$-binding sites [81-83].

Studies using CHIP-Chip and CHIP-seq on MCF7 breast cancer cells have revealed that ER $\alpha$ binds to 5000-10,000 locations [84-86]. However, only $<5 \%$ of these ER $\alpha$ binding sites (ERBs) are located in the proximal region of ER $\alpha$ 
target genes and conserved in the mouse genome [79, 87]. Most of these ERBs are distally located from targets genes and function as distal-cis-regulatory elements, generating a complex numbers of loops and anchors to bring the receptor binding sites closer to the transcription initiation site [85, 88]. CHIP-seq in the mouse mammary gland identified close to 6000 high confidence ERBs, with half of them enriched in ERE, PAX2, SF1 and AP1 motifs located at distal enhancer regions [89].

Transcriptional activity can also be regulated in a ligandindependent manner through downstream events of receptor tyrosine kinases (RTKs) activated by growth factors such as EGF, IGF-1 or TGF $\alpha$ [38]. Although ligand independent, these effects can be blocked by an anti-estrogen [90, 91]. This can affect either AF-1 on serine residues via phosphorylation by cyclin/Cdk2, MAPK or GSK3, thereby modulating ligand-independent activation of $\mathrm{ER} \alpha$, or $\mathrm{AF}-2$, in particular on Y537 where ligand binding is located [38, 92]. These modifications were shown to be particularly essential for the genomic effects of ER $\alpha$, in particular for the recruitment of transcriptional co-activators [93-96]. Thus, phosphorylation integrates these signaling pathways, such as epidermal growth factor receptor (EGFR)/human epidermal growth factor receptor 2 (HER2) into a complex cross-talk network with estrogen signaling. [92, 97].

The first cistrome of ER $\alpha$ has been performed in 2006 [84] and allowed to identify close to ERBs, some pioneer factors bound to DNA, in particular FOXA1 "ForkHead Box A1" [98], FOXM1 "ForkHead Box M1" [99], raising the idea that these pioneer factors control accessibility of $\mathrm{ER} \alpha$ on chromatin [100]. The same goes for the PBX1 factor [101], and for the factor GATA3 "GATA Binding Protein" [102]. The crucial role of these pioneer factors for the ER $\alpha$ response was demonstrated when FOXA1 and AP2gamma binding to several sites is decreased upon ER $\alpha$ silencing [103] (see also Chapter 4.2 for their roles in the mammary gland development).

\section{The membrane "non-genomic" actions of ERa}

A small fraction of the ER $\alpha$ is found at the plasma membrane where it activates the so-called "rapid", "nongenomic", or MISS for "Membrane-Initiated Steroid Signaling", which induces multiple signaling pathways $[49,104]$ and creates cross-talk between membrane and nuclear signaling $[21,22]$ (Fig. 2). The first rapid effect was described in 1967 when AMPc production was found to be increased within minutes in response to $17 \beta$-estradiol in the uterus [105]. The hypothesis of receptors, localized to the plasma membrane was then emitted but was controversial until 1977, when E2 binding was observed in membrane isolated from endometrial cells and hepatocytes [106]. Meanwhile, high number of data has shown that E2 rapidly activates $\mathrm{G}$ proteins, and a number of kinases such PI3K, P21ras, c-Src/ERK1-2 [21, 107]. Membrane ER $\alpha$ has near identical affinity for E2 than nuclear ER $\alpha$ and originates from the same transcript, but its abundance is very low (around 3\% as compared to nuclear ER $\alpha$ ) [108]. The so-called membrane ER $\alpha$ is localized within lipid rafts called caveolae within the plasma membrane, and S522A mutant of ER $\alpha$ was $60 \%$ less effective than wt ER $\alpha$ in binding caveolin-1 [109]. The receptor will thus form a real signaling platform made up of several proteins such as caveolin, striatin, $\mathrm{Src}, \mathrm{G}$ proteins or even growth factors. Striatin directly binds to amino acids $183-253$ of $\mathrm{ER} \alpha$, targets ER $\alpha$ to the cell membrane, and serves as a scaffold for the formation of an $E R \alpha-G_{\alpha i}$ complex [110]. Post-translational modifications, such as palmitoylation on Cys 447 (451 in mice) allows membrane anchoring by its palmitate $[111,112]$ and the membrane-initiated signaling (MISS). Transient methylation of arginine 260 has also been observed to induce ER $\alpha$ interaction with the $\mathrm{p} 85$ subunit of PI3K and Src, recruiting also the focal adhesion kinase (FAK) in this complex [113].

Membrane ER $\alpha$ effects were studied using transgenic mouse models mutated either for the palmitoylation site (ER $\alpha-C 451 \mathrm{~A}$, murine counterpart of human C447) [114, 115], or the methylation site (R264A, murine counterpart of human R260) [116]. Rapid signaling was also blocked by overexpression of a peptide that prevents ERs from interacting with the scaffold protein striatin (the disrupting mouse peptide) [117]. This membrane localization is crucial on endothelial cells where membrane ER $\alpha$ are coupled to eNOS in a functional signaling module that may regulate rapid NO synthesis and acceleration of re-endothelialization by E2 (reviewed in [21]).

To rigorously dissociate the genomic and non-genomic activities of E2, John Katzenellenbogen has developed two pharmacological tools to specifically activate the rapid membrane signaling: (i) the Estrogen-dendrimer conjugate (EDC), which can cross the plasma membrane but cannot enter the nucleus due to its charge and size [118] and (ii) the "pathway preferential estrogens" (PaPEs) which only activate non-genomic signaling, due to their very low affinities and rapid dissociation rates [119]. About $25 \%$ of genes responding to E2 also respond to EDC in MCF7 cells [120]. In contrast, the specific inhibition of PI3K, MAPK or even c-Src kinases by chemical inhibitors lead to a significant deregulation of the transcriptional response induced by E2, demonstrating that estrogen signaling interacts with other pathways allowing the establishment of a complete transcriptional response [120]. The integration of non-genomic actions of E2 at the chromatin level was also perfectly illustrated by the work of Miguel Beato's laboratory. Five minutes after hormone treatment, the cytoplasmic signaling cascade $\mathrm{Src} / \mathrm{Ras} / \mathrm{Erk}$ is activated via an interaction of 
the progesterone receptor with ER $\alpha$ leading to chromatin remodeling and cell proliferation [121].

In view of these studies, it is, therefore, difficult to functionally dissociate these two actions of estrogenic signaling. It is conceivable that, according to the cell type, differentiation and environment, genomic and membrane-initiated signaling (MISS) can act i) in concert, participating synergistically in the transcriptional initiation of hormone receptors in general, through post-translational modifications and epigenetic modifications of the chromatin, or ii) independently following the concept of moonlighting proteins [122, 123], playing one role in the extranuclear compartment, as already demonstrated in the endothelium, and one genomic, transcriptional role in the nuclear compartment.

\section{Mammary development and cell lineages}

\section{Overview of the post-natal mammary development and its hormonal context}

Comprehensive reviews on mammary development have been recently published [4-6]. An overview of each mammary developmental stage and their different hormonal contexts is provided below and illustrated in Fig. 3.

The mammary gland consists of a ramified epithelial tree embedded into a fatty stroma. When fully differentiated, the mammary tree is composed of milk-secreting alveoli connected by branching ducts (Fig. 3). In ducts and alveoli, the mammary epithelium is composed of an inner layer of luminal cells lining a lumen and an outer layer of basal myoepithelial cells sitting on a basement membrane (Fig. 4A). During lactation, the secretory luminal cells produce milk components, whereas the contractile myoepithelial cells serve for milk expulsion $[1,124,125]$.

In mouse females, the mammary tree remains rudimentary until puberty. At about 4 weeks of age, initiation of puberty triggers ductal elongation and branching, a process associated with elevated levels of GH and $17 \beta$-estradiol (E2), $[2,8,126]$ (Fig. 3). Cell proliferation mainly occurs at the tips of growing ducts within specialized bulbous structures, the terminal end buds (TEBs), that are composed of several inner layers of luminal-type cells and an outer layer of basal-type cells, known as body and cap cells, respectively [127]. TEBs drive ductal progression through the fat pad, with coordinated cell proliferation, differentiation, apoptosis and migration events [128-130]. At sexual maturity, TEBs regress and ductal elongation ceases. Estrogen and progesterone levels fluctuate with the recurrent estrus cycles, peaking during the pre-ovulatory (proestrus and estrus) and post-ovulatory (diestrus) phases, respectively [126, 131]. Cell proliferation and apoptosis successively occur with each cycle, leading to the formation of side branches and nascent alveolar buds that wax at the diestrus stage and partially regress thereafter [126, 131, 132].

During pregnancy, the mammary secretory tissue undergoes a massive expansion and prepares for milk production. Alveolar buds are formed all over the ductal tree and progressively develop into secretory alveoli that will be mature and fully functional upon lactation [1]. These processes are accompanied by an early surge of estrogen followed by a peak of progesterone. Concomitantly, levels of prolactin increase [126, 131]. Around parturition, progesterone levels abruptly drop down resulting in induction of labor. Prolactin levels remain high throughout lactation together with oxytocin, a hormone that controls myoepithelial cell

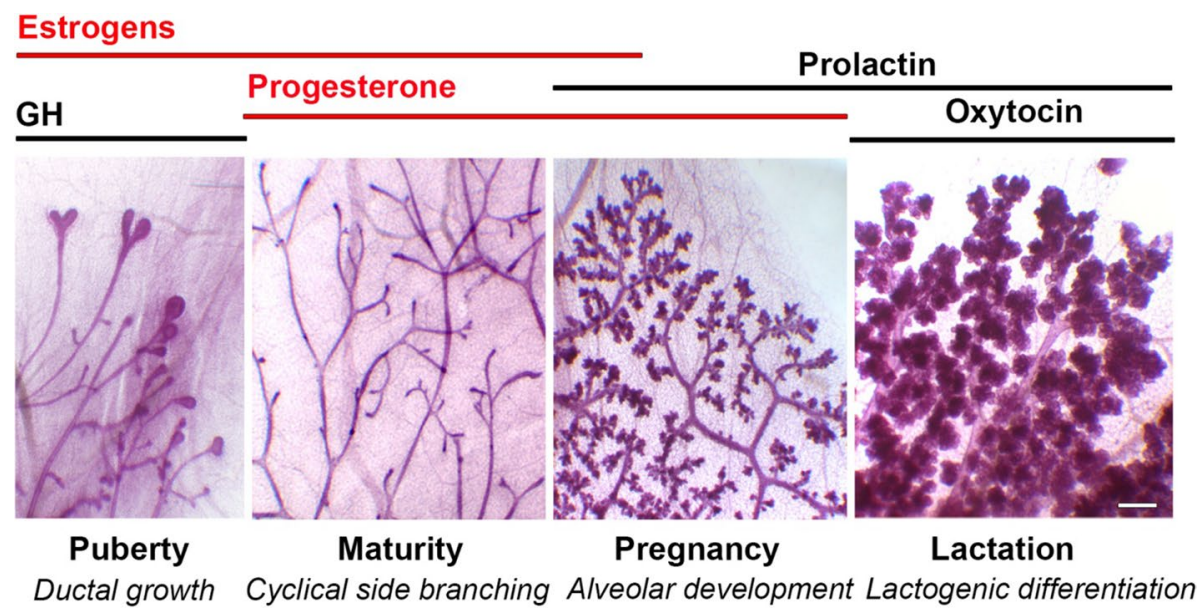

Fig. 3 Hormonal context of the major stages of the post-natal mouse mammary development. From left to right: images of carmine-stained whole mounts from 6-week-old pubertal, 12-week-old adult virgin, 16-day-pregnant and 2-day lactating mice. The pubescent gland is characterized by the presence of terminal end buds (TEBs) at the tips of the growing ducts. The steroid hormones, estrogens and progesterone, are in red whereas the peptide hormones are in black. $G H$ growth hormone. Bar: $0.25 \mathrm{~mm}$ 
A

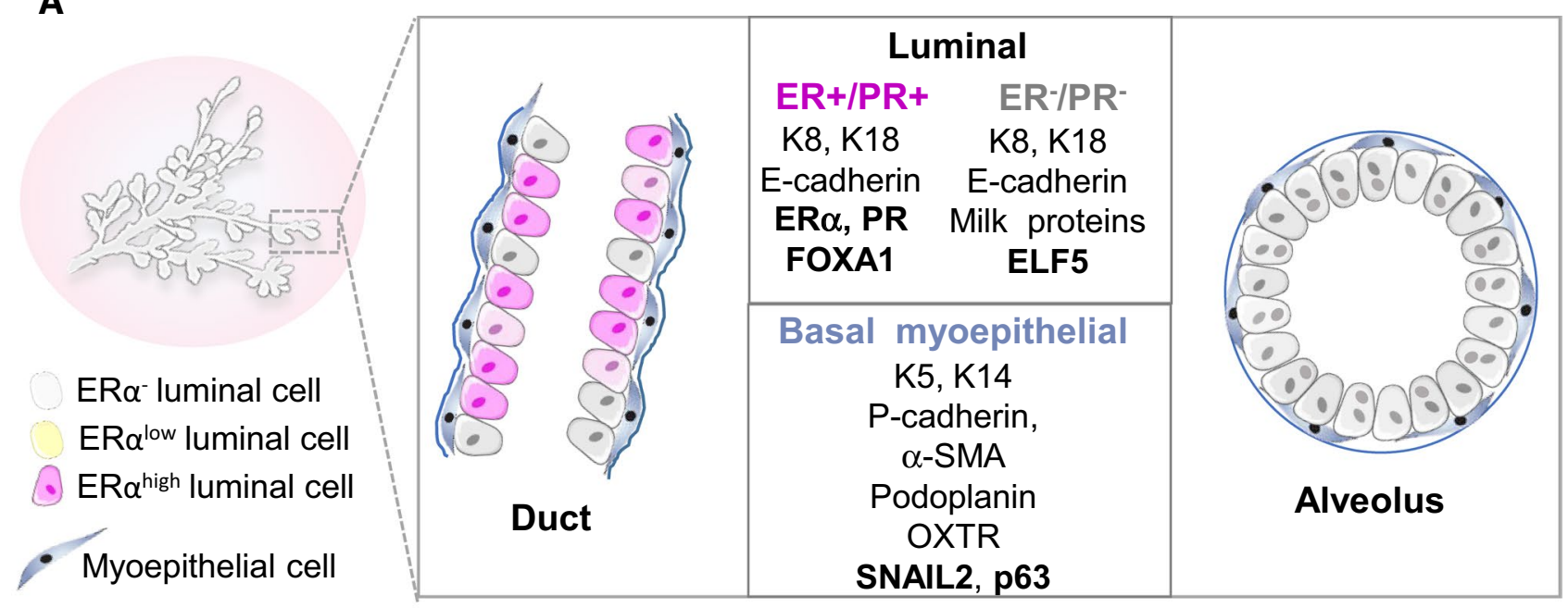

B

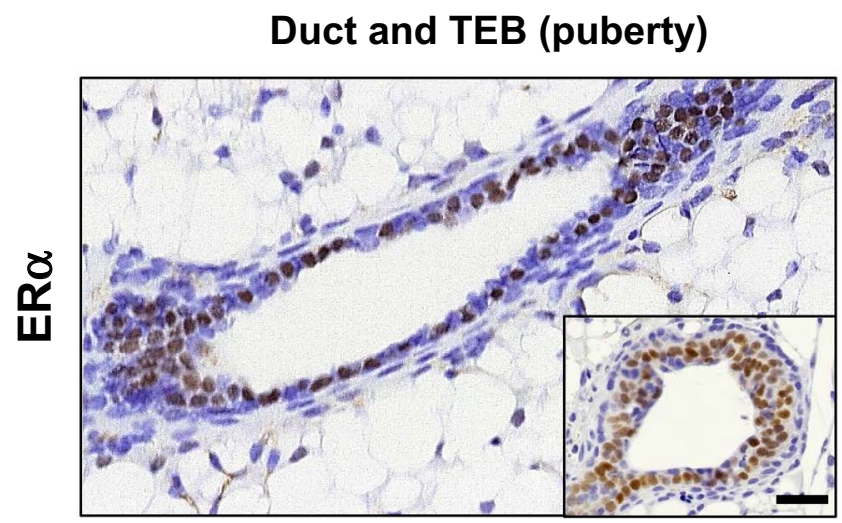

\section{Alveoli (pregnancy)}

Fig. 4 Organization of the mammary bilayer and localization of ER $\alpha$-expressing cells. A Schematic representation of mammary duct and alveolus and main specific markers of the basal myoepithelial, $\mathrm{ER} \alpha$-positive and -negative luminal cell lineages. Ductal ER $\alpha^{\text {high }}$ cells express nuclear ER $\alpha$ as detected by IHC whereas ER $\alpha^{\text {low }}$ cells express ER $\alpha$ transcripts without detectable nuclear staining. Keratins (K5, K14, K8, K18); $\alpha$-smooth muscle actin ( $\alpha$-SMA); oxytocin receptor (OXTR). B: ER $\alpha$ expression in ductal and alveolar struc-

contractility and milk ejection $[1,125,133]$. At weaning, the secretory tissue goes through a controlled process of cell death leading to involution and the gland returns to a pre-pregnant-like state until a novel cycle of gestation and lactation [6].

Ovariectomy of prepubertal females impedes mammary development, whereas administration of exogeneous estrogens restores its growth, resulting in morphological changes similar to those observed at puberty $[9,134]$. Noticeably, the response of the mammary tissue to estrogen stimulation is dose dependent. Low-to-moderate doses induce TEB formation and ductal elongation, while these processes are inhibited at higher doses [135]. This dose response effects underline the complex action of estrogen signaling on mammary gland and may have a physiological significance since tures, as revealed by IHC on PFA-fixed paraffin sections, using mouse monoclonal anti-ER $\alpha$ (Santa Cruz, sc-542, MC-20, described in [212]). Left: sections through a duct and a TEB (insert) from a pubertal mouse. Right: section through a group of alveoli from a pregnant mouse. Unlike ductal, alveolar luminal cells rarely display ER $\alpha$ nuclear expression. The arrowhead points to an ER $\alpha$ cell located in the stroma. Bars, $50 \mu \mathrm{m}$ and $25 \mu \mathrm{m}$

E2 levels are lower during the pubertal growth than during pregnancy.

Thus, elevated levels of circulating estrogens are associated with two major morphogenetic events, the pubertal ductal growth and the onset of alveolar expansion at gestation. Of note, signaling of mammotropic hormones synergizes at multiple levels. In particular, estrogens induce the expression of progesterone receptor (PR) and prolactin receptor (PRLR) transcripts, highlighting the pivotal role of ER $\alpha$ signaling in the hormonal response of the developing mammary epithelium [136-138]. 


\section{Mammary basal and luminal lineages}

It is now established that stem cells drive the post-natal mammary development. Pioneering orthotopic transplantation studies have shown that basal cells isolated from the adult mammary epithelium were able to regenerate bilayered ducts and alveoli, even at single cell level, whereas luminal cells had no significant regenerative potential [139-141]. This observation, confirmed by numerous subsequent transplantation assays, initially supported the notion that basaltype multipotent stem cells generated the myoepithelial and luminal cell lineages during puberty and pregnancy [4].

However, recent data from lineage-tracing experiments revealed that in situ, the post-natal mammary development and its homeostasis are essentially sustained by distinct basal and luminal unipotent stem cells [142-146]. Two distinct luminal lineages have been identified, relying on the presence or absence of ER $\alpha$ expression [144, 145] (Fig. 4A). The ER $\alpha$-positive lineage is viewed as a hormone-sensing entity acting through paracrine mechanisms on basal and luminal ER $\alpha$-negative cells, whereas the ER $\alpha$-negative lineage is largely committed to milk secretion [3, 131, 147]. Interestingly, recent data have shown that under regenerative conditions and upon oncogene expression, adult basal cells can reactivate a multipotency program that is restricted in situ by luminal cells through secretion of tumor necrosis factor [148].

\section{Characteristics of the ERa luminal cell lineage}

\section{Distribution of $\mathrm{ERa}^{+}$luminal cells within the developing mammary epithelium}

Immunohistochemical (IHC) studies have shown that ER $\alpha$ is expressed in the nuclei of both mammary epithelial and stromal cells [9]. The presence of epithelial but not stromal ER $\alpha$ turned to be essential for mammary morphogenesis [12].

Throughout development, nuclear ER $\alpha$ is absent from the basal myoepithelial cells and confined to the luminal layer. Interestingly, the proportion of $\mathrm{ER} \alpha^{+}$cells in the luminal compartment varies according to the developmental stage of the gland [145, 149-151]. Absent at birth, ER $\alpha$ was detected in about half of luminal cells at post-natal day 7 , a proportion maintained during the pubertal growth [138, 145]. During puberty, ER $\alpha$ is present in ductal luminal cells and in luminal body cells of TEBs [149, 150] (Fig. 4B). In post-pubertal virgin mice, ducts still comprise at least $50 \%$ of $\mathrm{ER} \alpha^{+}$luminal cells. This percentage decreases to about $5 \%$ at the end of pregnancy, the remaining positive cells being primarily located in ducts. During lactation, the luminal layer of the functional alveoli consists of ER $\alpha$ negative secretory cells $[145,150]$ (Fig. 4A).

Interestingly, detection of ER $\alpha$ transcripts in situ using RNAscope indicated that the status of ER $\alpha$ expression in luminal cells seems more complex than that observed by IHC [138]. This approach highlighted the existence of three luminal subsets in the mammary epithelium of pubertal females: $20 \%$ of luminal cells were found negative for both ER $\alpha$ mRNA and protein, $40 \%$ positive for ER $\alpha$ mRNA but negative for the protein (termed ER $\alpha^{\text {low }}$ ) and $40 \%$ positive for both ER $\alpha$ mRNA and protein (termed $E R \alpha^{\text {high }}$ ). Whether $\mathrm{ER} \alpha^{\text {high }}$ and $\mathrm{ER} \alpha^{\text {low }}$ cells represent mature and progenitor cells or reflect a continuous gradient in ER $\alpha$ expression levels remains to be determined. Another open question is whether ER $\alpha^{\text {low }}$ cells express membrane ER $\alpha$ and constitute a particular subset of estrogen-sensing cells. Indeed, in endothelial cells, ER $\alpha$ acts at the cell membrane level but cannot be visualized in the nucleus by immunostaining [21].

\section{$\mathrm{ERa}^{+}$luminal cells as hormone-sensing cells}

$P G R$ is an established estrogen-target gene encoding the nuclear receptor isoforms, PR-A and PR-B [131, 152, 153]. Both isoforms (hereafter referred to as $P R$ ) have been detected in the mouse mammary epithelium, but only PR-B is required for a proper mammary development [154, 155].

Consistent with the role of estrogens in inducing PGR, most luminal cells staining positive for $\mathrm{ER} \alpha^{+}$by IHC display a nuclear expression of PR, in mouse as well as in human mammary epithelium [156-158]. Moreover, the luminal cells from ER $\alpha$ knock-out mice completely lack nuclear PR expression [138, 159-161]. Interestingly, analysis of transgenic mice lacking either AF- 1 or AF-2 domain of ER $\alpha$ revealed that $\mathrm{PR}$ expression in mammary luminal cells is primarily AF-2 dependent, i.e., ligand-dependent [138]. This study also indicated that PR is preferentially expressed by the $\mathrm{ER} \alpha^{\text {high }}$ luminal subset.

Mammary luminal cells co-expressing $\mathrm{ER} \alpha$ and PR $\left(\mathrm{ER} \alpha^{+} \mathrm{PR}^{+}\right)$are perceived as the main targets of the ovarian steroid hormones and consequently are termed hormonereceptor positive, hormone-sensing or sensor cells [4, 131, 162]. Of note, several gene expression profiles of mouse mammary epithelial cells have shown that the luminal cell population expressing Esrl and Pgr also contain high levels of Prlr transcripts, indicating that it responds to prolactin stimulation, in addition to estrogens and progesterone [7, 162-166]. However, the lack of reliable antibodies against PRLR has hampered the precise localization of this receptor in situ. 
Table 1 Major surface markers used to separate mouse mammary basal and luminal cells and enrich ER $\alpha$-positive and ER $\alpha$-negative luminal cell populations by flow cytometry after exclusion of endothelial and hemopoietic cells by CD31 and CD45 surface staining

\begin{tabular}{|c|c|c|c|c|}
\hline Surface marker & Basal & Luminal $\mathrm{ER} \alpha^{+}$ & Luminal ER $\alpha^{-}$ & References \\
\hline \multicolumn{5}{|c|}{ Used to separate basal from luminal cells } \\
\hline $\mathrm{CD} 24$ & + & ++ & ++ & {$[173]$} \\
\hline EpCAM & + & ++ & ++ & {$[164]$} \\
\hline CD29 ( $\beta 1-$-Itg) & ++ & + & + & {$[139]$} \\
\hline $\begin{array}{l}\text { CD49f } \\
(\alpha 6-\text { Itg })\end{array}$ & ++ & + & + & {$[140]$} \\
\hline Podoplanin & ++ & - & - & {$[167]$} \\
\hline \multicolumn{5}{|c|}{ Used to enrich $\mathrm{ER} \alpha^{+}$and $\mathrm{ER} \alpha^{-}$luminal cells } \\
\hline CD61 ( $\beta 3$-Itg) & ++ & - & + & {$[169]$} \\
\hline $\begin{array}{l}\text { CD49b } \\
(\alpha 2-\text { Itg })\end{array}$ & ++ & - & + & {$[164]$} \\
\hline c-Kit & - & - & + & {$[171]$} \\
\hline CD14 & - & - & + & [163] \\
\hline ICAM-1 & ++ & - & + & [172] \\
\hline Sca-1 & - & + & - & {$[141]$} \\
\hline $\begin{array}{l}\text { CD133 (Prom- } \\
\text { inin-1) }\end{array}$ & - & + & - & [141] \\
\hline
\end{tabular}

\section{Enrichment of ERa ${ }^{+}$Iuminal cells by flow cytometry}

The use of a panel of cell surface markers for flow cytometry has allowed a clear separation of the mammary basal, luminal and stromal cell populations and, in addition, enabled the enrichment the $\mathrm{ER} \alpha^{+} \mathrm{PR}^{+}$and $\mathrm{ER} \alpha^{-} \mathrm{PR}^{-}$luminal cell subsets. The most commonly used markers are summarized in Table 1. A large fraction of them are adhesion molecules, such as EpCAM, CD24, ICAM-1 and the integrin chains $\alpha 2, \alpha 6, \beta 1$ and $\beta 3$.

In the human mammary epithelium, $\mathrm{ER} \alpha{ }^{+} \mathrm{PR}^{+}$luminal cells are characterized by a lower $\alpha 6$ (CD49f) integrin expression than $\mathrm{ER}^{-} \mathrm{PR}^{-}$cells and CD49f separates quite nicely the two populations [168].

In mouse, $\mathrm{ER} \alpha^{+} \mathrm{PR}^{+}$luminal cells have been enriched using differential expression of Sca-1, Prominin-1 (CD133), c-Kit, CD14, ICAM-1 and the $\alpha 2-(C D 49 b)$ and $\beta 3$ (CD61) integrin chains [141, 163, 164, 169-172] (Table 1). None of these markers perfectly discriminate the two luminal populations. However, some of them (Sca-1, Prominin-1 and ICAM-1) display a robust expression in various mouse genetic backgrounds, at protein and mRNA levels [141, 162, 163, 166, 172, 174, 175].

Most ER $\alpha^{+} \mathrm{PR}^{+}$luminal cells are positive for Sca- 1 and Prominin-1 (Table 1). So that the use of these markers enables a convenient enrichment of the hormone-sensing population [141, 144, 163, 175]. This was confirmed by purifying the ER $\alpha$-positive lineage following its tracing by YFP expressed under the control of ER $\alpha$ promoter [145]. Although ICAM-1 and CD49b largely mark the ER $\alpha^{-} \mathrm{PR}^{-}$ luminal cell population (Table 1), they are expressed by a minor subset positive for Sca-1 and enriched in $\mathrm{ER}^{+} \mathrm{PR}^{+}$ cells. This Sca- $1^{+}$ICAM- $1^{+}$(or Sca- $1^{+}$CD $49 b^{+}$) subset has a colony-forming potential, attributed to $\mathrm{ER} \alpha^{+}$luminal progenitors [164, 172].

Mammary gland function and ER $\alpha$ expression are not altered in Prominin-1 knockout females, suggesting that this glycoprotein is not an essential regulator of the $\mathrm{ER} \alpha^{+} \mathrm{PR}^{+}$lineage [176]. Similarly, loss of ICAM-1 and CD 49 b does not result in a deleterious mammary phenotype $[42,172]$.

\section{Main molecular features of $\mathrm{ERa}^{+}$luminal cells}

Global transcriptomic profiles of the $\mathrm{ER} \alpha^{+} \mathrm{PR}^{+}$and $\mathrm{ER} \alpha^{-} \mathrm{PR}^{-}$luminal cell populations enriched by flow cytometry have been established in human and mouse mammary tissues [7, 163, 164, 166, 174]. More recently, comprehensive and unbiased gene expression analyses across different stages of mammary development were performed using single cell RNA-seq [162, 177-179]. Apart from Esrl and $P g r$, a few genes encoding transcription factors and coregulators (Foxal, Tbx3, Msx2, Myb and Cited l) have been reported as specifically expressed in the hormone-sensing cell population of the adult gland [7, 162-164]. Of note, the hormonesensing cell population is devoid of Elf5, a key transcription factor controlling the alveolar cell fate [7, 144, 163, 166, 180]. Elf5 specifically signs the ER $\alpha^{-}$PR- luminal cell subset together with milk protein genes, such as $\beta$-casein and WAP (whey acidic protein).

In agreement with the gene expression data, IHC studies have shown that the vast majority of $E R \alpha^{+}$luminal cells co-expresses FOXA1, an inducer of ER $\alpha$ expression that controls its transcriptional activity [98, 150, 181]. Consistently, GATA3, a transcription factor regulating both ER $\alpha$ and FOXA1 mRNA expression, is present in ER $\alpha^{+}$luminal cells [158, 182-184]. A correlation was also observed between the presence of $\mathrm{ER} \alpha$ and $\mathrm{TBX} 3$, a transcriptional repressor involved in the generation of the hormone-sensing cell population [185]. CITED1, a transcriptional coactivator of ER $\alpha$, has been detected in a subset of ductal and TEB luminal cells (most probably $\mathrm{ER} \alpha^{+}$) during puberty [181, 186].

Transcriptomic profiles and gene expression analysis by qRT-PCR also revealed that the $\mathrm{ER} \alpha^{+} \mathrm{PR}^{+}$cell population highly expresses several genes encoding secreted factors, such as Areg (encoding amphiregulin), Tnfsfl1 (encoding RANKL) and Wnt4 [7, 162, 163, 166]. WNT4 and RANKL are effectors of progesterone signaling. They play a major role in ductal side branching and alveologenesis during 
pregnancy by inducing the expansion of basal and $\mathrm{ER} \alpha^{-} \mathrm{PR}^{-}$ luminal cells through paracrine mechanisms downstream of PR activation [152, 187-189].

Areg is an established ER $\alpha$-target gene strongly induced in the mammary glands of ovariectomized females stimulated by E2 and restricted to luminal cells expressing Esr 1 and $P g r$, as seen by single-cell RNA-seq analysis [190, 191]. Areg transcripts have been detected in situ in a subset of luminal cells expressing PR that most probably belong to the ER $\alpha^{\text {high }}$ population $[138,190]$. The role of AREG downstream of ER $\alpha$ signaling in the mammary epithelium will be described in the section dedicated to the transgenic mouse models.

A recent single cell RNA-seq analysis comparing mammary glands from young (3-4 month-old) and aged (13-14 month-old) virgin mice revealed age-dependent alterations in cell type composition and gene expression that potentially reflect age-associated hormonal changes [192]. The proportion of hormone-sensing cells decreases with age and their transcriptomic profile is characterized by the up-regulated expression of Tph1 (encoding tryptophan hydroxylase 1) and $\operatorname{Arg} 1$ (encoding arginase 1). In line with previous works $[162,177]$, this study also identified a rare luminal population that co-expressed hormone-sensing and secretory-alveolar lineage specific genes, suggesting a dual differentiation potential. Transcriptional data were further supported by in situ detection of luminal cells co-expressing $\mathrm{ER} \alpha$, PR and milk-related markers (MFGE8, LTF). Notably, the abundance of this population whose precise in vivo function remains to be determined strongly decreases with aging.

\section{$\mathrm{ERa}^{+}$unipotent stem cells}

Early observations on tissue sections revealed that unlike $\mathrm{ER}^{-} \mathrm{PR}^{-}$luminal cells, $\mathrm{ER}^{+} \mathrm{PR}^{+}$cells rarely display proliferation markers [156, 161]. Hormone-sensing cells were, therefore, for long time, considered as mature luminal cells with poor growth ability. In addition, it has been suggested that $\mathrm{ER} \alpha$ expression is lost before the proliferative response, as stimulation with E2 led to undetectable ER $\alpha$ expression within $4 \mathrm{~h}$ that reappeared by $24 \mathrm{~h}$ [134]. Nonetheless, later on, several studies using nucleotide analog incorporation assays indicated that $\mathrm{ER} \alpha{ }^{+} \mathrm{PR}^{+}$luminal cells substantially proliferate in particular during puberty, during the estrus stage and at the beginning of gestation [149, 151, 174, 193]. Moreover, in vitro colony-formation assays on isolated cells showed that although less clonogenic than $\mathrm{ER} \alpha^{-} \mathrm{PR}^{-}$cells, the $\mathrm{ER} \alpha^{+} \mathrm{PR}^{+}$luminal cell subset defined by the double expression of Sca-1 and ICAM-1 (or CD49b) harbored colony-forming cells, considered as expanding progenitors [141, 164, 172].

Two recent studies using Prominin-1 or ER $\alpha$ expression to map $\mathrm{ER} \alpha^{+}$cell fate in situ confirmed that $\mathrm{ER} \alpha^{+}$luminal cells expand during mammary development and in addition showed that these cells exclusively generate an ER $\alpha^{+}$luminal progeny $[145,175]$. Specifically, by tracing ER $\alpha$-positive luminal cells with YFP in transgenic mice, Van Keymeulen et al. reported that lineage-restricted $\mathrm{ER} \alpha^{+}$luminal stem/ progenitor cells ensure the expansion of $\mathrm{ER} \alpha^{+}$luminal cells during puberty and sustain their long-term renewal during repeated cycles of pregnancy and lactation [145]. It is not clear yet whether the construct selected in this study allowed the tracing of both $E R \alpha^{\text {high }}$ and $E R \alpha^{\text {low }}$ cells or preferentially that of ER $\alpha^{\text {high }}$ cells, which would impact the interpretation of the data.

$\mathrm{ER} \alpha^{+}$luminal stem/progenitor cells remain to be fully characterized. RNA-seq analysis of single mammary epithelial cells isolated from adult mouse indicated that high levels of Aldh1a3, Lypd3, Kit and Cd14 could discriminate $\mathrm{ER} \alpha+$ luminal stem/progenitor cells from their differentiated progeny [162]. However, these genes are also highly expressed in ER $\alpha$-negative luminal stem/progenitor cells. The analysis of three independent RNA-seq data sets suggests the existence of a common ALDH1 A $3^{+} \mathrm{ER} \alpha^{-}$luminal stem/progenitor cell for both $\mathrm{ER} \alpha^{+}$and $\mathrm{ER} \alpha^{-}$cell lineages [162, 178, 179].

The molecular mechanisms and signals from the niche that control the $\mathrm{ER} \alpha^{+}$luminal cell lineage remains to be explored in detail. Notch1 has been identified as a master determinant of the mammary luminal cell differentiation. Its activation represses the basal-specific transcription factor $\Delta \mathrm{Np} 63$ [194] and can reprogram basal cells into ER $\alpha$ negative luminal cells in vivo [195]. Notably, ER $\alpha$ and Notch1 expression in post-natal luminal cells is mutually exclusive [144], suggesting a negative cross-talk between Notch and ER $\alpha$ signaling. Consistently, former studies performed with breast cancer cell lines showed that stimulation by E2 inhibited Notch1 activity [196].

A recent work reports that R-spondin 1 (RSPO1), a niche factor secreted by the ER $\alpha$-negative luminal cells, regulates ER $\alpha$ expression through paracrine mechanisms [197]. RSPO1 is known to bind LGR receptors and synergize with WNT4 to enhance Wnt/ $\beta$ cat signaling in mammary basal cells. Using a luminal cell-specific Rspol-deficient transgenic mouse model, the authors found that loss of RSPO1 resulted in reduced mammary side branching in adult virgin females, with a decreased ER $\alpha$ expression and signaling activity in luminal cells. RSPO1 activated G-protein coupled cAMP signaling in $\mathrm{ER} \alpha^{+}$luminal cells through LGR4, independently of the $\mathrm{Wnt} / \beta \mathrm{cat}$ axis. 


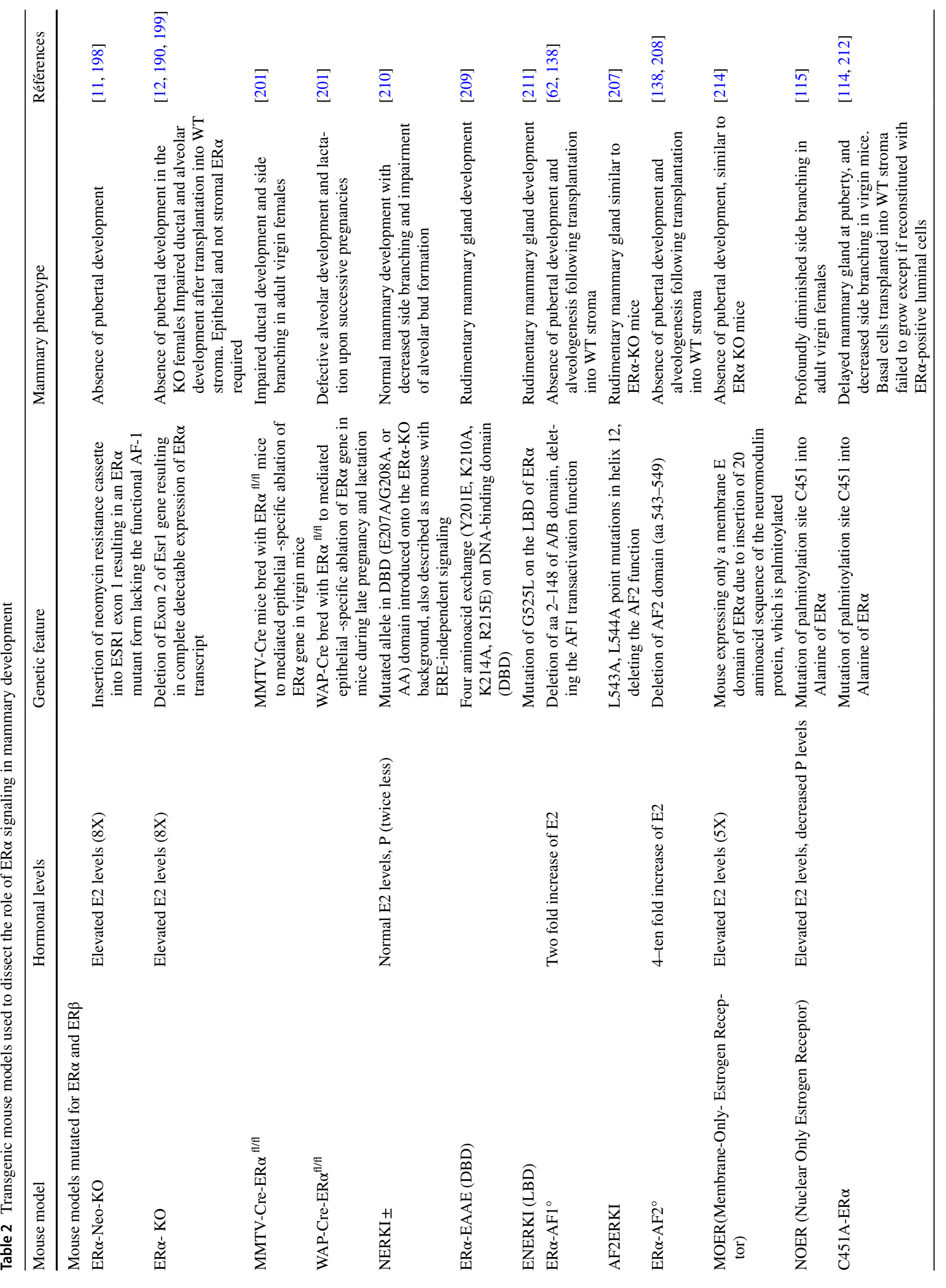




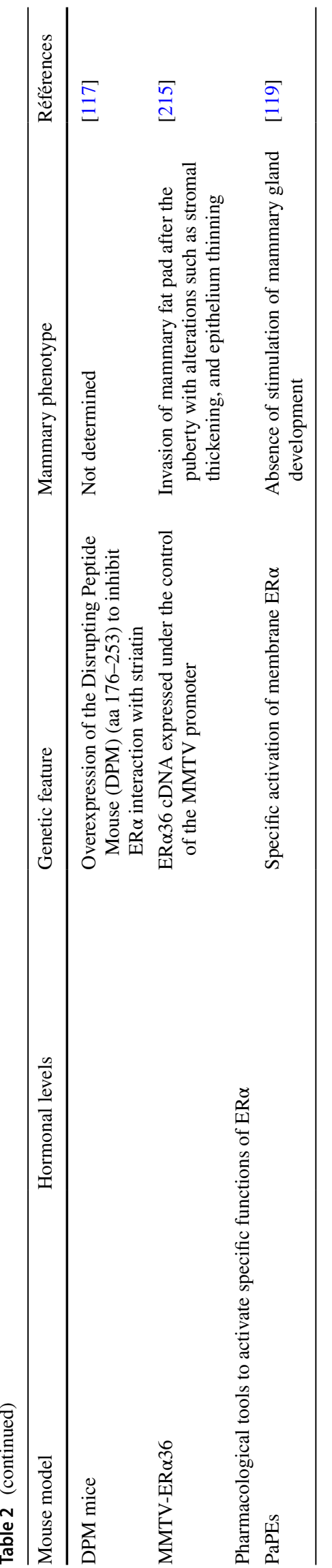

Mammary phenotype of transgenic mouse models impacting ERa signaling

\section{Mouse models mutated for ERa}

The transgenic mouse models used to dissect the role of $\mathrm{ER} \alpha$ signaling in mammary development and function are presented in Table 2.

The first studies were conducted using two distinct knockout mice termed ER $\alpha$ NeoKO $[11,198]$ and ER $\alpha-K O$ [199]. The mammary epithelial tree of these mice was normally developed at the prepubertal stage indicating that the early stages of mammary morphogenesis are independent of ER $\alpha$ signaling. In contrast, TEB formation and ductal growth were abrogated in the pubescent mutant females $[11,12]$. Of note, the ER $\alpha$-KO mouse completely lacks ER $\alpha$ transcript expression, whereas the ER $\alpha \mathrm{NeoKO}$ was found later to retain a substantial ER $\alpha$ function, by producing a spliced mRNA that gives rise to a receptor lacking part of the ligand-independent AF-1 domain, a form reminiscent of that from the $\mathrm{ER} \alpha-\mathrm{AF} 1^{\circ}$ deficient mice $[62,200]$.

As ER $\alpha$-KO mice presented endocrine abnormalities that could indirectly impact their mammary phenotype, orthotopic transplantation assays were performed. This strategy allows to compare the development of wild-type (WT) and mutant mammary epithelial fragments grafted into cleared contralateral mammary fat pads of a WT recipient mouse and thereby reveal mammary epithelium intrinsic phenotype [3]. Unlike WT, ER $\alpha-\mathrm{KO}$ ducts grafted into a WT stroma completely failed to develop, even after a hormonal stimulation of the host mouse mimicking pregnancy, demonstrating that ER $\alpha$ expression in epithelial cells is essential for ductal and alveolar development [12].

The importance of epithelial ER $\alpha$ expression for pubertal mammary gland development was further confirmed using a Cre-Lox-based conditional knockout model (MMTV-Cre$\left.\mathrm{ER} \alpha^{\mathrm{f} / \mathrm{fl}}\right)$ targeting all luminal cells [201]. This work also included the analysis of the mammary phenotype of WAP$\mathrm{Cre}-\mathrm{ER} \alpha^{\mathrm{f} / / \mathrm{fl}}$ females, a model in which ER $\alpha$ was deleted from luminal cells at late pregnancy and during lactation. Although nuclear ER $\alpha$ is absent from WAP-expressing milk secretory cells, lobuloalveolar development and milk production were perturbed in the WAP-Cre-ER $\alpha^{\mathrm{f} / \mathrm{fl}}$ females upon successive pregnancies. Conceivably, the maintenance of early alveolar progenitors, potentially analogous to the so-called parity-identified mammary epithelial cells that express WAP and survive involution might be affected by $\mathrm{ER} \alpha$ loss either directly or indirectly [202].

Importantly, transplantation assays using a mix of WT and $\mathrm{ER} \alpha-\mathrm{KO}$ epithelial cells indicated that ER $\alpha$ in epithelial cells acts in a paracrine manner on neighbor cells [12]. Activation of ER $\alpha$ by E2 was found to induce, in addition 
to PR expression, the secretion of amphiregulin (AREG) in the epithelium [190]. AREG was the most abundant EGFlike growth factor in the pubertal mammary gland, with a maximum expression $12 \mathrm{~h}$ after E2 stimulation in ovariectomized mice. Analysis of AREG-KO and mix WT-KO mammary grafts showed that AREG acts as an essential paracrine mediator of ER $\alpha$ signaling and is required for the massive epithelial cell proliferation, TEB formation and ductal elongation during puberty. Nonetheless, AREG-KO mammary grafts, although poorly developed, expressed PR and consistently could undergo side branching and alveologenesis in a pregnant host, whereas $\mathrm{ER} \alpha-\mathrm{KO}$ were unable to do so $[12,190]$.

Additional studies showed that the transmembrane form of AREG is cleaved into a mature peptide by metalloproteinase domain containing protein 17 (ADAM17) and promotes signaling in stromal cells through binding to EGFR [203]. EGFR activation induces expression of growth factors in stromal cells, in particular members of the FGF family that regulate mammary epithelial growth in a paracrine fashion [130]. ER $\alpha$, AREG and EGFR knockout mice display similar mammary phenotypes, characterized by a lack of ductal development [204-206].

A rudimentary mammary gland similar to the one observed in ER $\alpha$-KO mice was observed in the ER $\alpha$-AF2KI mice, in which L543A and L544A point mutations in helix 12 were introduced, deleting the AF2 function [207]. More recently, the roles of AF1 and AF2 transactivation functions of ER $\alpha$ have been explored independently, using the $\mathrm{ER} \alpha-\mathrm{AF} 1^{\circ}$ and the $\mathrm{ER} \alpha-\mathrm{AF} 2^{\circ}$ mice generated by P. Chambon and colleagues, respectively $[62,138,208]$. This second $\mathrm{ER} \alpha-\mathrm{AF} 2^{\circ}$ mouse model was obtained by deleting the aminoacids 543 to 549 in the helix 12 [208]. The data showed that deletion of AF-1 or AF-2 blocks pubertal ductal growth and alveologenesis and by means of grafting assays, revealed an unexpected complexity of ER $\alpha$ signaling, linked to cellpopulation-specific functions of AF1 and AF2. ER $\alpha^{\text {high }}$ luminal cells were found to require both AF-1 and AF-2 to transcribe crucial downstream effector genes such as Areg, Pgr, Prlr and Wnt4. On the other hand, ER $\alpha^{\text {low }}$ luminal cells appeared essential for ductal development during puberty but growth inhibitory during pregnancy. This population depends on the AF2 transcriptional response that also controls transcript levels of genes linked to cell motility, adhesion and plasticity [138].

Two mouse models have been mutated into the DNAbinding domain to dissect DNA-binding-dependent vs. ERE-independent transcriptional regulation elicited by ER $\alpha$ : first, the ER $\alpha$-EAAE (ENERKI) mouse harboring four aminoacid exchange (Y201E, K210A, K214A, R215E) on DNA-binding domain (DBD) [209], and second, the NERKI mouse mutated into the $\mathrm{P}$ box of the first zinc finger of the DBD (E207A/G208A)[210]. While results observed with the NERKI mouse bred onto the ER $\alpha$-KO mice can be questioned due to an unclear figure even in WT, the ER $\alpha$-EAAE clearly shows a rudimentary mammary gland development [209] similar to that observed in ER $\alpha-\mathrm{KO}$, demonstrating the importance of the DNA-binding nuclear response.

In another model, a specific point mutation (G525L) was introduced on the ER $\alpha$ ligand-binding domain (LBD) to distinguish ligand-induced and ligand-independent ER $\alpha$ actions. This model confirmed that estrogen-induced activation of ER $\alpha$ is crucial for the development of female reproductive tract and mammary gland [211].

As detailed in Sect. 1.2 (Fig. 2), ER $\alpha$ outside the nucleus can activate rapid/non-genomic/membrane-initiated steroid signals (MISS). To analyze the potential implication of MISS in tissue development, two groups have generated similar knock-in mouse models mutated for the palmitoylation site (theoretically the same point mutation), i.e., the ER $\alpha-C 451 \mathrm{~A}$ [114] and the NOER mice [115]. In contrast to mice deleted for nuclear effects of ER $\alpha$, NOER and ER $\alpha-C 451 \mathrm{~A}$ mice have a developed mammary gland that completely filled the fat pad but showed diminished ductal side branching and decreased number of blunted duct termini [115, 212].

The specific mechanisms that control the ability of basal and luminal cells to respond to membrane ER $\alpha$ signaling have been investigated in details using the ER $\alpha$ C451A mouse model and grafting assays [212]. The data demonstrated that mutation of the palmitoylation site of $\mathrm{ER} \alpha$ was necessary in promoting intercellular communications essential for mammary gland development. In fact, absence of the membrane ER $\alpha$ impairs the expansion of $\mathrm{ER} \alpha$ positive luminal cells that further alters the required paracrine signaling and the final ductal outgrowth. Transcriptional analysis also points the requirement of Greb1 gene expression. Greb-1 is well-known as an early response gene in the ER $\alpha$-regulated pathway and was shown to be a chromatin-bound ER coactivator essential for ER-mediated transcription that stabilizes interactions between ER and additional cofactors [89, 213]. Importantly, loss of membrane signaling in luminal cells also altered Jak2 and Stat5a gene expression, a pathway found at the crossroad of hormonal and growth factor signaling which uncovers an important role of membrane ER $\alpha$ as a key regulator of growth factor response [212].

A transgenic mouse deprived of both nuclear and cytoplasmic functions of ER $\alpha$ was also developed by expressing only a functional $\mathrm{E}$ domain of ER $\alpha$ at the plasma membrane in an ER $\alpha-\mathrm{KO}$ background to study the specific membrane actions of ER $\alpha$ [214]. This MOER mouse harbors a rudimentary mammary gland development similar to the ER $\alpha-K O$ mice. The absence of pubertal mammary ductal growth following activation of only membrane actions of ER $\alpha$ was also confirmed using a pharmacological tool, the 
"pathway preferential estrogens" (PaPEs). These ligands were synthesized to preserve their essential chemical and physical features to bind ER $\alpha$ with an affinity that allowed preferential induction of the extranuclear-initiated signaling/ MISS pathway. PaPEs did not stimulate mammary gland fat pad filling nor breast cancer cells growth [119].

Finally, to investigate the potential function of the short $\mathrm{ER} \alpha-36$ isoform, only present in humans, a MMTV-ER $\alpha 36$ transgenic mouse strain was generated allowing specific expression of ER $\alpha 36$ cDNA in mammary epithelial cells. The mammary epithelium of the mutant females normally invaded the fat pad but significant defects were observed, such as duct dilation, stromal thickening, epithelium thinning and leakage [215].

Collectively, the data obtained from mouse models revealed the complex status of ER $\alpha$ expression in the mammary epithelium and the multiple implications of ER $\alpha$ signaling in the control of mammary development. Genomic actions include induction of crucial paracrine effectors such as AREG required for ductal growth and of PR expression necessary for the expansion of the secretory tissue. Both AF-1 and AF-2 genomic actions of ER $\alpha$ are crucial for a normal mammary development during puberty and pregnancy. In addition, non-genomic effects of ER $\alpha$ signaling that modulate intercellular communications participate in the regulation of mammary morphogenesis. It is possible that the levels of circulating estrogens, lower in puberty than during pregnancy, direct and trigger differential ER $\alpha$ responses in estrogen-sensing cells.

\section{Mouse models mutated for pioneer factors and coregulators of ERa}

As previously mentioned, the transcriptional activity of ER $\alpha$ depends on its interaction with coregulators. Consistently, several of these coregulators appeared to be critical for TEB formation, ductal branching and alveologenesis during mammary gland development (reviewed in [181]).

FOXA1 was the first pioneer factor identified for ER $\alpha$, specifically required for ER $\alpha$ induced transcription of cyclin D1 [216]. Co-expression of FOXA1 and ER $\alpha$ was observed not only in the pubertal gland [150] but also in luminal breast cancers and cell lines [217-219]. The crucial role of FOXA1 in mammary morphogenesis was confirmed using orthotopic and renal capsule transplantation of mammary anlagen from Foxal KO mice [150]. These assays revealed that ductal elongation and TEB formation were severely impaired in the absence of FOXA1, whereas alveologenesis, although limited, could occur in pregnant hosts. IHC studies showed that FOXA1-deficient luminal cells lacked ER $\alpha$ and PR expression, whereas FOXA1 was expressed in ER $\alpha-\mathrm{KO}$ mammary gland, indicating that FOXA1 acts upstream of $\mathrm{ER} \alpha$ and controls its expression and signaling.
Similar to ER $\alpha$ and FOXA1, GATA3 is required for TEB formation and ductal growth during puberty. Accordingly, the targeted loss of GATA3 in the mammary epithelium leads to a defective generation of ductal ER $\alpha$-expressing cells, an accumulation of ER $\alpha$-negative luminal progenitors and a block in differentiation, revealing a pivotal role for GATA3 in the maintenance of the luminal compartment [182, 220, 221].

Collectively, these studies revealed a complex interplay between ER $\alpha$, GATA3 and FOXA1 [181]. GATA3 regulates FOXA1, which in turn regulates ER $\alpha$, while GATA-3 and $\mathrm{ER} \alpha$ regulate each other positively. Furthermore, these factors colocalize at transcription sites upon E2 stimulation and form a tripartite complex that ensures optimal transcriptional activation [183, 222-224]. ER $\alpha$ also upregulates FOXM1, another forkhead transcription factor that down-regulates GATA3 expression and may balance ER $\alpha$ and GATA3 interaction during mammary gland development. FOXM1 was found to promote luminal cell proliferation as opposed to GATA3 that mediated luminal differentiation [225]. The chromatin complex formed by ESR1, GATA3, and FOXA1 thus coordinately orchestrates mammary luminal lineage commitment and estrogen response.

More recently, ten-eleven translocation (TET2), a chromatin modifier which mediates DNA demethylation, was found highly expressed in mammary luminal cells [226]. Targeted deletion of TET2 in the mammary epithelium through MMTV-Cre showed that loss of TET2 increased ductal branching and TEB numbers in pubescent females but impaired alveolar development at pregnancy. FACS analysis of the mutant glands revealed an increased proportion of mammary basal cells with stem cell activity, a diminished subset of ER $\alpha^{+}$luminal cells and an aberrant commitment of luminal cells towards a mixed basal/luminal phenotype. TET2 was found to interact with the transcription factor FOXP1 and forms a chromatin complex that mediates demethylation of Esrl, FoxAl and Gata3. TET2 loss led to a decreased expression of ER $\alpha$, FOXA1 and GATA3 expression both at protein and mRNA levels that profoundly perturbed the luminal lineage commitment and the balance between the basal and the luminal lineages and thereby altered mammary development.

Among the main co-activators of ER $\alpha$ are also members of the p160 family (SRC-1, SRC-2 and SRC-3), as mentioned in Sect. 1. SRC-1 disruption in vivo showed decreased mammary ductal branching and also decreased number and size of alveoli during pregnancy, even though milk production was normal [227]. In contrast, SRC-2 is not required for early post-natal mammary gland development, in both virgin and pregnant mice [228]. However, work from Mukherjee and colleagues [229] reported that SRC-2 may be important for progesterone-induced signaling. As SRC-2, SRC-3 is not essential for E2-stimulated ductal growth in virgin mice, 
but is required for progesterone-stimulated cellular proliferation and glandular differentiation during pregnancy [230]. In summary, SRC-1 is an important coregulator of ER $\alpha$ for ductal branching at puberty and SRC-3 is probably the primary coactivator for PR in breast [231].

CITED 1 (Cbp/p300-interacting transactivator with Glu/ Asp-rich carboxy-terminal domain) was identified as another important coregulator of ER $\alpha$ controlling the pubertal mammary ductal morphogenesis, as shown by the analysis of CITED1 homozygous null mice [186].

Among the main corepressors, the role of REA in mammary gland development during puberty or pregnancy was, respectively, studied using conditional tissue-specific deletion of one or both alleles of REA under the control of $P g r$ or Wap promoter, respectively [232]. Interestingly, at both puberty and pregnancy, opposite effects were observed depending of the homozygous or heterozygous deletion, demonstrating that the REA is crucial for mammary gland development at all stages, puberty, pregnancy and lactation, with crucial gene dosage-dependent actions. Rip140deficient mice and transgenic Rip140 overexpressing mice have also been generated [233]. The Ripl40 KO mice displayed minimal ductal branching at maturity. In contrast, the ductal network of the Rip140 overexpressing mice was more branched, exhibited hyperplasic growth and developed denser alveolar structures. In fact, RIP140 expression is essential in both the epithelium and the stroma and acts as a rate-limiting factor required for ductal development in the mammary epithelium. RIP140 acts as a coregulator of ER $\alpha$ and is recruited to a number of its target gene promoters/ enhancers, such as Areg, Pgr, Ccndl and Stat5a.

\section{Estrogens acts in concert with other growth factors}

Numerous data have demonstrated that estrogens act in concert with growth factors and the cooperation between estrogens and growth hormone $(\mathrm{GH})$ in governing pubertal development has been particularly studied. The main downstream effector of pituitary-derived GH signaling is IGF-1 (insulin growth factor 1) primarily produced by liver but also locally by mammary stromal cells $[3,130]$. The Igfl-KO mice have an impairment of mammary development and lack TEBs, a phenotype that cannot be restored by the injection of estrogen while the injection of IGF-1 alone for 5 days improves development [234, 235]. The receptor involved in this signaling was investigated using embryonic $I G F-I R$ mammary gland transplantation into WT stroma, because null mice die at birth. These data directly demonstrated that IGF-IR expressed by TEB cells is necessary for proliferation and ductal morphogenesis [236]. In contrast, these defects are corrected during pregnancy, indicating that exposure to signals from pregnancy is able to compensate for the loss of otherwise important mammary signaling pathways. This restoration during pregnancy may also result from changes in mammary cell sensitivity to insulin-like signals mediated by the Insulin receptors (IR). Indeed, there is genetic evidence that the IR can mediate the growth promoting function of IGF-2 [237], that was also confirmed by showing that IGF-2 was a downstream mediator of prolactin-induced alveologenesis and an upstream regulator of cyclin D1 expression [238]. IGF-1 may play a crucial role during post-natal development in concert with ER $\alpha$ while IGF-2 might drive the prolactin effect during alveologenesis. Moreover, overexpression of IGF1R in epithelial cells in mice leads to abnormal development of the ducts (hyperplasia) and tumor formation in vivo [239].

Tian and colleagues have particularly studied ER $\alpha / \mathrm{IGF} 1 \mathrm{R}$ co-signaling using a mouse model overexpressing human IGF1 in the mammary gland under the control of the basalspecific bK5 promoter [240]. This ectopic IGF-1 expression in myoepithelial cells induced paracrine effects on adjacent epithelial cells. Interestingly, this study shows that ectopic IGF-1 is able to activate different signaling pathways dependent on the pubertal status of mice. Indeed, the results show an increase in p-Akt associated with the activation of mTOR in the prepubertal transgenic glands whereas in the post-pubescent transgenic glands, the activated pathways are related to the Ras/Raf/MAPK signaling cascade. These observations can be correlated with the change in the expression of ER $\alpha$ in the mammary gland. ER $\alpha$ is more expressed in the pubescent gland than in the post-pubescent gland, which corresponds to negative feedback by the E2 ligand. It is then proposed that IGF1/IGF1R/ER $\alpha$ signaling may activate different cytoplasmic effectors depending on the proliferative state of the mammary gland.

\section{Estrogens and breast cancers}

\section{ERa-positive luminal breast cancers}

Considerable interest has focused on luminal cells in the context of mammary gland development and tumorigenesis, as most breast cancers are thought to originate from deregulated luminal cells, either negative or positive for ER $\alpha$ [4, 241]. ER $\alpha$-positive tumors account for $70-80 \%$ of all breast cancers and belong to the two luminal molecular subtypes, $\mathrm{A}$ and $\mathrm{B}$, characterized by a low and high proliferation index, respectively [13-15]. The most frequent special histological subtype is the invasive lobular carcinoma (ILC) that clusters with luminal A and B subtypes and is characterized by a loss of E-cadherin expression [15].

Most ER $\alpha$-positive breast cancers depend on estrogen for their growth and ER $\alpha$ expression is predictive for responsiveness to endocrine therapies targeting the E2/ER $\alpha$ 
pathway. It is important to mention that histologically, ER $\alpha$ positive tumors are defined as having at least $1 \%$ of tumor cells exhibiting a nuclear ER $\alpha$ staining as assessed by IHC, without a clear consensus of the used antibodies [14, 15]. Hence, ER $\alpha$-positive tumors are highly heterogeneous with a broad range of ER $\alpha$ expression spanning from $1 \%$ to nearly $100 \%$. In addition, they display an important intratumoral heterogeneity, as highlighted by a recent work using imaging mass cytometry at the single cell level [242, 243].

Blockade of E2/ER $\alpha$ activity by administration of tamoxifen and aromatase inhibitors have major antitumor effects on ER $\alpha$-positive breast cancers and already benefited to millions of women [244]. This benefit is still observed when only a small fraction of breast cancer cells expresses ER $\alpha$, demonstrating the importance of blocking the expansion of this cell subset and its potential paracrine action. Nonetheless, late relapses at distant sites are often observed, compromising the long-term outcome of patients with ER $\alpha$-positive breast cancers. In addition, an important proportion of the patients do not respond to endocrine therapies and up to 50\% acquire resistance under treatment [245].

\section{Exposure to estrogens and breast cancers}

The impact of estrogens on breast cancer was first demonstrated more than a century ago by the British surgeon George Beatson who observed regression of a breast tumor following ovariectomy [246]. Nowadays, early and prolonged exposure to endogenous or exogenous estrogens during a woman's life is recognized as being a factor of major risk in developing a breast cancer, in particular an ER $\alpha$-positive subtype [247, 248]. Early menarche, late menopause, nulliparity or late first pregnancy are viewed as risk factors while breast feeding is considered as a protective factor [247, 249, 250]. The timing of hormone exposure appeared as an important parameter since aberrant hormonal exposure prior to puberty or in early life has a more significant effect on breast cancer risk than late menopause, suggesting a particular susceptibility of the immature mammary gland to tumorigenesis [247].

The risk of breast cancer also increases among women who currently or recently used contemporary hormonal contraceptives as compared to non-users. This absolute increase in risk remains low but rises with longer durations of use [248, 251]. According to the big prospective Women Heath's Initiative (WHI) trial that evaluated risks of hormonal replacement therapy, the combination of conjugated equine estrogens plus medroxyprogesterone acetate led to an increased risk of breast cancer whereas hysterectomized women treated with estrogens alone (equine conjugates, without progestin) developed, quite unexpectedly, less breast cancer than women receiving a placebo [252, 253]. More recent analyses have shown that the levels of risks varied between types of hormonal replacement therapies, with higher risks when progestins were used in the combination with estrogens (as compared to the natural progesterone), and again, for longer duration of use [254]. The identification of safer estrogenic compounds is, therefore, necessary to improve the benefit / risk balance in patients on hormonal replacement therapies and contraception.

\section{Mutations of ESR1 in human breast tumors}

The most frequent mutated genes in ER $\alpha$-positive breast cancers are PIK3CA, GATA3, MAP3K1, KMT2C and TP53. Mutation of CDH1 (encoding E-cadherin) or loss of alleles are common in the lobular subtype (reviewed in [15, 255]). In contrast, ESR 1 mutations are rare (less $<1 \%$ ) in primary ER $\alpha$-positive breast cancers [256] but between 20 and $40 \%$ of ESR1 mutations are observed in metastatic breast cancer and influence response to hormone therapy (reviewed in [256-260]). In fact, these mutations emerge under the pressure of chemotherapy and successive anti-hormonal treatments, often after aromatase inhibitor (AI) treatment. They include highly recurrent ESR1 mutations encoding Y537C/ $\mathrm{S} / \mathrm{N}$ with a prevalence reaching $60 \%$ of mutations detected in metastatic breast cancers [261, 262]. Another mutation in the LBD is the D538G, at a high frequency of 20\% [260]. This mutated tyrosine Y537 has been particularly involved in the growth of mammary cancer cells and xenografts following phosphorylation by Src tyrosine kinases (p56 $6^{\mathrm{lck}}$ and p60 $\left.{ }^{\text {c-src }}\right)$ [263-267]. In addition, mammary MCF7 cancer cell lines stably expressing the ER $\alpha-Y 537 \mathrm{~S} / \mathrm{N}$ and D538G present higher proliferation than wild-type expressing cells. Moreover, these mutations not only confer constitutive, hormone-independent activity of ER $\alpha$ but also lead to change in transcriptional responses that mediate cancer progression and confer anti-estrogen resistance by altering the conformation of the ligand-binding domain of ER $\alpha$, which leads to a stabilized agonist state and an altered antagonist state [268, 269]. Expression of the ESR1Y537S mutation also induced an epithelial-mesenchymal transition (EMT) in cells and exhibited enhanced migration [270]. Other mutations, such as K303R, E380Q, S463P, V534E, Y535S, L536R were also found with different frequencies [271-275]. A summary of the characteristics of all these ER $\alpha$ mutants in breast cancers have been recently reviewed in [276].

More recently, genomic rearrangement events producing ESRl fusion genes have been reported in endocrine therapy resistance [277]. These events include in-frame fusions such as inter-chromosomal ESR1 translocations with the YAP1 gene (ESR1-e6 > YAP1), the protocadherin $11 \mathrm{X}$-linked gene, PCDH11X (ESR1-e6 > PCDH11X) and the nucleolar protein 2 homolog gene, NOP2 (ESR1-e6 $>$ NOP2), and 2 intra-chromosomal translocations with the A-kinase anchoring protein 12 gene, AKAP12 (ESR1-e6 > AKAP12) and 
the DNA polymerase eta gene, POLH (ESR1-e7 > POLH). These ESR1 fusion genes not only led to endocrine resistance but also induced epithelial-mesenchymal transition (EMT) leading to metastasis.

Finally, there are also numerous changes in the chromatin landscape and epigenetic mechanisms regulating the biology of ER $\alpha$-positive breast cancer that can orchestrate the resistance to breast cancer treatments (reviewed in [278]).

\section{Models of ERa-positive breast cancers}

Establishing in vivo models mimicking the complex biology of ER $\alpha$-positive breast cancers remains an active field of research (reviewed in [279]. Since the 1980s, different approaches have been used including chemically induced carcinomas in rats, genetically engineered mouse models (GEMMs), human cell line xenografts and patient derived xenografts (PDX), each having their own advantages and limitations.

GEMMs have contributed significantly to the field of breast cancer research and translational oncology, however, most of them develop ER $\alpha$-negative mammary tumors [280]. Nonetheless, the broadly used MMTVPyMT mouse model that expresses polyoma middle $\mathrm{T}$ (PyMT) oncogenic protein in the mammary epithelium recapitulates some aspects of ER $\alpha$-positive breast cancers. This model rapidly develops spontaneous luminal-like ER $\alpha$-positive premalignant mammary lesions, sensitive to tamoxifen, which further progress to ER $\alpha$-negative mammary carcinoma forming lung metastases [281, 282]. In MMTV-PyMT females, ER $\alpha$ signaling favors tumor onset, tumor growth and pulmonary metastasis [282]. Loss of TET2 that profoundly alters ER $\alpha$ signaling and mammary development was recently found to promote the growth of invasive MMTV-PyMT tumors and confer resistance to tamoxifen in vivo [226].

A conditional tetracycline-responsive transgenic mouse model overexpressing ER $\alpha$ in mammary epithelial cells was generated that developed proliferative lesions such as atypical ductal and lobular hyperplasia and $\mathrm{ER} \alpha^{+} \mathrm{PR}^{+}$ductal carcinoma in situ by 4 weeks of age [283]. Moreover, a transgenic mouse expressing the mutation found in human tumors was created by expressing the HA tagged K303R-ER $\alpha$ under the control of the MMTV promoter [284]. Although more alveolar budding was observed in 4-month-old mutant K303R-ER $\alpha$ transgenic mice as compared to WT-ER $\alpha$ MMTV mice, no hyperplasia was observed in older mice.

Among recent GEMMs of interest are the Stat1-null and the $\mathrm{BlgCre} ; \mathrm{KiRas}^{(\mathrm{G} 12 \mathrm{~V})}$ mice. Stat1-null females spontaneously develop mammary adenocarcinomas of luminal origin that comprise more than $90 \% \mathrm{ER}^{+}$and $\mathrm{PR}^{+}$cells and depend on estrogen for tumor engraftment and progression. Although accelerated by parity, the tumor latency of about
10 months hampers an easy use of this model [285]. Conditional expression of the mutated human KiRas under the control of the Blg promoter, active during pregnancy and lactation, leads to the development of invasive ductal carcinomas within 3-9 months after induction. These tumors, positive for ER $\alpha$ and PR but negative for HER2, mimic the luminal A subtype and respond to anti-estrogen treatment [286].

As PI3KCA mutations are commonly found in luminal breast cancer subtypes, two groups used inducible GEMMs to investigate the impact of an oncogenic PI3KCA mutant targeted either in basal or luminal cells and analyze its contribution to tumor heterogeneity [287, 288]. Interestingly, PI3KCA mutant expression in basal cells induced the formation of luminal $\mathrm{ER} \alpha^{+} \mathrm{PR}^{+}$mammary tumors while its expression in the whole luminal population gave rise to luminal $\mathrm{ER}^{+}{ }^{+}$mammary tumors and basal-like $\mathrm{ER} \alpha^{-} \mathrm{PR}^{-}$ tumors. Thus, the same mutation can induce plasticity in normally lineage-restricted cell types and result in different tumor phenotypes, reinforcing the importance of the cell of origin in breast cancer development [4]. The use of specific promoters for addressing pertinent oncogenic mutations in the ER $\alpha^{+}$luminal cell lineage should lead to the design of novel GEMMs, providing further insights into initiation and progression of the $\mathrm{ER} \alpha^{+}$luminal breast cancers.

Finally, many PDX models have been successfully established for pre-clinical breast cancer research, however, the take rates of ER $\alpha$-positive tumor samples transplanted in the mammary fat pad of immunocompromised mice were noticeably low [289, 290]. Recently, intraductal grafting has enabled the establishment of ER $\alpha$-positive PDX derived from fresh human tumor biopsies with significantly improved take rates [291, 292]. These PDX models that recapitulate early developmental stages of ER $\alpha$-positive luminal breast cancers should be of great help to evaluate aggressiveness and responsiveness to endocrine therapy. The same strategy was further used to design a model of $\mathrm{ER} \alpha$-positive ILC and test novel therapeutic approaches [293]. Gene expression analysis of the ILC-derived samples revealed an ECM remodeling signature with an enrichment in LOXL1, a targetable member of the lysyl oxidase family. LOXL1 inhibition through a pan LOX inhibitor was found to reduce tumor growth and metastasis by human lobular cell lines injected intraductally.

\section{Conclusion}

Since the cloning of ESRI in 1986, the field has made considerable advances in deciphering the molecular mechanisms of ER $\alpha$ signaling through genomic and non-genomic actions and in addition, piecing together the role of ER $\alpha$ in luminal cells and in mammary gland development and 
function. These advances largely rely on the recent technological developments, including sophisticated transgenic mouse models, high-throughput sequencing and advanced confocal microscopy.

Analysis of the mammary phenotype from multiple transgenic mouse models, targeting ER $\alpha$ or its main coregulators, has clearly shown that ER $\alpha$ signaling does not play a role before puberty, whereas it is essential for pubertal ductal growth and subsequent alveologenesis. In the last decade, the ER $\alpha$-expressing luminal cell lineage has been better characterized in terms of ER $\alpha$ transcript and protein levels, molecular profiles, stem/progenitor cell content, proliferation ability and differentiation potential. The crucial role of ER $\alpha$-expressing luminal cells in sensing hormonal stimuli and sending paracrine signals to their neighbors, the basal and ER $\alpha$-negative luminal cells, has been confirmed and refined. These signals control the amplification of the ductal cells during puberty and the expansion of the secretory tissue during gestation.

At the mechanistic level, significant progresses have been made in deciphering the role of ligand-independent and ligand-dependent activation functions of ER $\alpha$. In particular, it has been shown that AF1 and AF2 domains have cell population-specific functions but are both required for a proper expression of paracrine mediators [138]. The target cells of the non-genomic membrane actions of ER $\alpha$ signaling within the mammary epithelium remain to be precisely identified. However, data from transgenic mouse models revealed that this non-classical mode of action, active for example in endothelial cells, participates in the control of mammary development by regulating intercellular communication [212]. Similarly, classical and nonclassical progesterone signaling pathways through nuclear and membrane receptors have been identified in mammary epithelial and cancer cells [153].

Genomic and non-genomic ER $\alpha$ signaling likely act in concert according to the developmental stage of the mammary gland, its hormonal context and the differential levels of circulating estrogens. Undoubtedly, a better understanding of this complex interplay will shed more light on the control of the mammary basal and luminal cell lineages and their deregulation during the tumorigenic process.

The upstream regulation of $\mathrm{ER} \alpha^{+}$expression in the mammary epithelium is less understood than its action. An important direction for future research is to further define the niche of $\mathrm{ER} \alpha^{+}$luminal cells and identify niche signals regulating the development and homeostasis of this lineage. In the mammary ducts, luminal ER $\alpha$-positive cells directly interact with luminal ER $\alpha$-negative and basal cells that display-specific cell-cell contacts and secrete multiple growth factors able to specifically impact ER $\alpha^{+}$cell function in a juxtacrine or paracrine manner. In addition, luminal $\mathrm{ER} \alpha^{+}$cells can interact with resident intra-epithelial macrophages, a population lying between the luminal and basal cell layers that was recently revealed using highresolution imaging [294].

Deciphering the complexity of the mammary stroma (fibroblasts, adipocytes, immune cells) and analyzing its interplay with the epithelial compartment during normal development and tumorigenesis also define a broad research area [243]. Numerous mammary stromal cells express ER $\alpha$ and, therefore, respond to estrogen stimulation.

Finally, it is worth mentioning that several emerging topics could not be developed in the present review, such as chromatin landscape, epigenetic regulation and non-coding RNAs. They all are actively investigated in the context of normal mammary development and breast cancers $[4,5]$. Collectively, these efforts should provide a better understanding on how the normal mammary tissue develops and evolves in the course of a woman life, and how the developmental programming is lost during breast cancer initiation.

Acknowledgements We thank Isabelle Bleuart for providing excellent technical support and advice regarding the histology (ENVT). The authors apologize to all the investigators whose work could not be cited here due to space limitations.

Authors' contributions MAD and FL performed the literature search and drafted the manuscript. MR drawed the figures and helped with writing. All authors reviewed and approved the publication.

Funding Some of the work summarized here performed at I2MCINSERM U1297 was supported by Institut National de la Santé et de la Recherche Médicale, Université et CHU de Toulouse, Faculté de Médecine Toulouse-Rangueil, Fondation pour la Recherche Médicale, Association pour la Recherche Contre le Cancer (PJA 20141201844 and PJA 20161204764 to F.L.) and La ligue Contre le Cancer- AriègeHaute-Garonne-Tarn. MAD is Chargée de Recherche Hors Classe at Institut National de la Santé et de la Recherche Médicale. Recent work was supported by a grant from the Ligue Contre le Cancer Ile de France (Comité de Paris RS19/75-67). MR was supported by a grant from the Agence Nationale de la Recherche- (BENEFIT to F.L.). SC was supported by a grant from the European Research Council (project 339847 MYODYN) during her PhD work.

Data availability Not applicable.

\section{Declarations}

Conflict of interests The authors declare that they have no conflict of interest.

Open Access This article is licensed under a Creative Commons Attribution 4.0 International License, which permits use, sharing, adaptation, distribution and reproduction in any medium or format, as long as you give appropriate credit to the original author(s) and the source, provide a link to the Creative Commons licence, and indicate if changes were made. The images or other third party material in this article are included in the article's Creative Commons licence, unless indicated otherwise in a credit line to the material. If material is not included in the article's Creative Commons licence and your intended use is not 
permitted by statutory regulation or exceeds the permitted use, you will need to obtain permission directly from the copyright holder. To view a copy of this licence, visit http://creativecommons.org/licenses/by/4.0/.

\section{References}

1. Anderson SM et al (2007) Key stages in mammary gland development. Secretory activation in the mammary gland: it's not just about milk protein synthesis! Breast Cancer Res 9(1):204

2. Macias H, Hinck L (2012) Mammary gland development. Wiley Interdiscip Rev Dev Biol 1(4):533-557

3. Brisken C, Ataca D (2015) Endocrine hormones and local signals during the development of the mouse mammary gland. Wiley Interdiscip Rev Dev Biol 4(3):181-195

4. Fu NY et al (2020) Stem cells and the differentiation hierarchy in mammary gland development. Physiol Rev 100(2):489-523

5. Slepicka PF, Somasundara AVH, Dos Santos CO (2020) The molecular basis of mammary gland development and epithelial differentiation. Semin Cell Dev Biol 114:93-112

6. Watson CJ, Khaled WT (2020) Mammary development in the embryo and adult: new insights into the journey of morphogenesis and commitment. Development 147(22):dev169862:dev169862

7. Lim E et al (2010) Transcriptome analyses of mouse and human mammary cell subpopulations reveal multiple conserved genes and pathways. Breast Cancer Res 12(2):R21

8. Brisken C, O'Malley B (2010) Hormone action in the mammary gland. Cold Spring Harb Perspect Biol 2(12):a003178

9. Daniel CW, Silberstein GB, Strickland P (1987) Direct action of 17 beta-estradiol on mouse mammary ducts analyzed by sustained release implants and steroid autoradiography. Cancer Res 47(22):6052-6057

10. Haslam SZ (1988) Local versus systemically mediated effects of estrogen on normal mammary epithelial cell deoxyribonucleic acid synthesis. Endocrinology 122(3):860-867

11. Bocchinfuso WP et al (2000) Induction of mammary gland development in estrogen receptor-alpha knockout mice. Endocrinology 141(8):2982-2994

12. Mallepell S et al (2006) Paracrine signaling through the epithelial estrogen receptor alpha is required for proliferation and morphogenesis in the mammary gland. Proc Natl Acad Sci USA 103(7):2196-2201

13. Sorlie T et al (2001) Gene expression patterns of breast carcinomas distinguish tumor subclasses with clinical implications. Proc Natl Acad Sci U S A 98(19):10869-10874

14. Hammond ME et al (2010) American society of clinical oncology/college of american pathologists guideline recommendations for immunohistochemical testing of estrogen and progesterone receptors in breast cancer. J Oncol Pract 6(4):195-197

15. Russnes HG et al (2017) Breast cancer molecular stratification: from intrinsic subtypes to integrative clusters. Am J Pathol 187(10):2152-2162

16. Jaiyesimi IA et al (1995) Use of tamoxifen for breast cancer: twenty-eight years later. J Clin Oncol 13(2):513-529

17. Jordan VC (2003) Tamoxifen: a most unlikely pioneering medicine. Nat Rev Drug Discov 2(3):205-213

18. Johnston SR, Dowsett M (2003) Aromatase inhibitors for breast cancer: lessons from the laboratory. Nat Rev Cancer 3(11):821-831

19. Mangelsdorf DJ et al (1995) The nuclear receptor superfamily: the second decade. Cell 83(6):835-839

20. Hamilton KJ et al (2017) Estrogen hormone biology. Curr Top Dev Biol 125:109-146
21. Arnal JF et al (2017) Membrane and nuclear estrogen receptor alpha actions: from tissue specificity to medical implications. Physiol Rev 97(3):1045-1087

22. Levin ER, Hammes SR (2016) Nuclear receptors outside the nucleus: extranuclear signalling by steroid receptors. Nat Rev Mol Cell Biol 17(12):783-797

23. Mosselman S, Polman J, Dijkema R (1996) ER beta: identification and characterization of a novel human estrogen receptor. FEBS Lett 392(1):49-53

24. Green $S$ et al (1986) Structural and functional domains of the estrogen receptor. Cold Spring Harb Symp Quant Biol 51(Pt 2):751-758

25. Greene GL et al (1986) Sequence and expression of human estrogen receptor complementary DNA. Science 231(4742):1150-1154

26. Kuiper GG et al (1996) Cloning of a novel receptor expressed in rat prostate and ovary. Proc Natl Acad Sci U S A 93(12):5925-5930

27. Thornton JW, Need E, Crews D (2003) Resurrecting the ancestral steroid receptor: ancient origin of estrogen signaling. Science 301(5640):1714-1717

28. Dolgin E (2017) The most popular genes in the human genome. Nature 551(7681):427-431

29. Couse JF, Korach KS (1999) Estrogen receptor null mice: what have we learned and where will they lead us? Endocr Rev 20(3):358-417

30. Antal MC et al (2008) Sterility and absence of histopathological defects in nonreproductive organs of a mouse ERbeta-null mutant. Proc Natl Acad Sci U S A 105(7):2433-2438

31. Ponglikitmongkol M, Green S, Chambon P (1988) Genomic organization of the human oestrogen receptor gene. EMBO J 7(11):3385-3388

32. Kos M et al (2001) Minireview: genomic organization of the human ERalpha gene promoter region. Mol Endocrinol 15(12):2057-2063

33. Reid G et al (2002) Human estrogen receptor-alpha: regulation by synthesis, modification and degradation. Cell Mol Life Sci 59(5):821-831

34. Lung DK, Reese RM, Alarid ET (2020) Intrinsic and extrinsic factors governing the transcriptional regulation of ESR1. Horm Cancer 11(3-4):129-147

35. Stanisic V, Lonard DM, O'Malley BW (2010) Modulation of steroid hormone receptor activity. Prog Brain Res 181:153-176

36. Berry M, Metzger D, Chambon P (1990) Role of the two activating domains of the oestrogen receptor in the cell-type and promoter-context dependent agonistic activity of the anti-oestrogen 4-hydroxytamoxifen. Embo J 9(9):2811-2818

37. Tora $\mathrm{L}$ et al (1989) The human estrogen receptor has two independent nonacidic transcriptional activation functions. Cell 59(3):477-487

38. Le Romancer M et al (2011) Cracking the estrogen receptor's posttranslational code in breast tumors. Endocr Rev 32(5):597-622

39. Ali S et al (1993) Modulation of transcriptional activation by ligand-dependent phosphorylation of the human oestrogen receptor A/B region. EMBO J 12(3):1153-1160

40. Metivier R et al (2001) Synergism between ERalpha transactivation function 1 (AF-1) and AF-2 mediated by steroid receptor coactivator protein-1: requirement for the AF-1 alphahelical core and for a direct interaction between the $\mathrm{N}$ - and C-terminal domains. Mol Endocrinol 15(11):1953-1970

41. Thomas RS et al (2008) Phosphorylation at serines 104 and 106 by Erk1/2 MAPK is important for estrogen receptor-alpha activity. J Mol Endocrinol 40(4):173-184

42. Chen $J$ et al (2002) The alpha(2) integrin subunit-deficient mouse: a multifaceted phenotype including defects 
of branching morphogenesis and hemostasis. Am J Pathol 161(1):337-344

43. Sarwar N et al (2006) Phosphorylation of ERalpha at serine 118 in primary breast cancer and in tamoxifen-resistant tumours is indicative of a complex role for ERalpha phosphorylation in breast cancer progression. Endocr Relat Cancer 13(3):851-861

44. Rajbhandari $P$ et al (2012) Regulation of estrogen receptor alpha $\mathrm{N}$-terminus conformation and function by peptidyl prolyl isomerase Pin1. Mol Cell Biol 32(2):445-457

45. Metivier R et al (2002) A dynamic structural model for estrogen receptor-alpha activation by ligands, emphasizing the role of interactions between distant $\mathrm{A}$ and $\mathrm{E}$ domains. Mol Cell 10(5):1019-1032

46. Zwart $\mathrm{W}$ et al (2010) The hinge region of the human estrogen receptor determines functional synergy between AF-1 and AF-2 in the quantitative response to estradiol and tamoxifen. J Cell Sci 123(Pt 8):1253-1261

47. Lonard DM, O'Malley BW (2012) Nuclear receptor coregulators: modulators of pathology and therapeutic targets. Nat Rev Endocrinol 8(10):598-604

48. McKenna NJ, Lanz RB, O'Malley BW (1999) Nuclear receptor coregulators: cellular and molecular biology. Endocr Rev 20(3):321-344

49. McKenna NJ, O'Malley BW (2002) Combinatorial control of gene expression by nuclear receptors and coregulators. Cell 108(4):465-474

50. Foulds CE et al (2013) Proteomic analysis of coregulators bound to ERalpha on DNA and nucleosomes reveals coregulator dynamics. Mol Cell 51(2):185-199

51. Liu $\mathrm{Z}$ et al (2014) Enhancer activation requires transrecruitment of a mega transcription factor complex. Cell 159(2):358-373

52. Kobayashi $\mathrm{Y}$ et al (2000) p300 mediates functional synergism between AF-1 and AF-2 of estrogen receptor alpha and beta by interacting directly with the N-terminal A/B domains. J Biol Chem 275(21):15645-15651

53. Yi P et al (2015) Structure of a biologically active estrogen receptor-coactivator complex on DNA. Mol Cell 57(6):1047-1058

54. Delage-Mourroux R et al (2000) Analysis of estrogen receptor interaction with a repressor of estrogen receptor activity (REA) and the regulation of estrogen receptor transcriptional activity by REA. J Biol Chem 275(46):35848-35856

55. Cavailles V et al (1995) Nuclear factor RIP140 modulates transcriptional activation by the estrogen receptor. EMBO J 14(15):3741-3751

56. Flouriot $\mathrm{G}$ et al (2000) Identification of a new isoform of the human estrogen receptor-alpha (hER-alpha) that is encoded by distinct transcripts and that is able to repress hER-alpha activation function 1. Embo J 19(17):4688-4700

57. Maaroufi Y et al (2000) Estrogen receptor of primary breast cancers: evidence for intracellular proteolysis. Breast Cancer Res 2(6):444-454

58. Horigome T et al (1988) Estradiol-stimulated proteolytic cleavage of the estrogen receptor in mouse uterus. Endocrinology 123(5):2540-2548

59. Barraille P et al (1999) Alternative initiation of translation accounts for a $67 / 45 \mathrm{kDa}$ dimorphism of the human estrogen receptor ERalpha. Biochem Biophys Res Commun 257(1):84-88

60. Ohe $\mathrm{K}$ et al (2018) HMGA1a induces alternative splicing of the estrogen receptor-alphalpha gene by trapping U1 snRNP to an Upstream Pseudo-5' Splice Site. Front Mol Biosci 5:52

61. Penot $\mathrm{G}$ et al (2005) The human estrogen receptor-alpha isoform hERalpha46 antagonizes the proliferative influence of hERalpha66 in MCF7 breast cancer cells. Endocrinology 146(12):5474-5484
62. Billon-Gales A et al (2009) The transactivating function 1 of estrogen receptor alpha is dispensable for the vasculoprotective actions of 17beta-estradiol. Proc Natl Acad Sci U S A 106(6):2053-2058

63. Abot A et al (2013) The AF-1 activation function of estrogen receptor alpha is necessary and sufficient for uterine epithelial cell proliferation in vivo. Endocrinology 154(6):2222-2233

64. Fontaine $\mathrm{C}$ et al (2020) The tissue-specific effects of different 17beta-estradiol doses reveal the key sensitizing role of AF1 domain in ERalpha activity. Mol Cell Endocrinol 505:110741

65. Murphy AJ et al (2009) Estradiol regulates expression of estrogen receptor ERalpha46 in human macrophages. PLoS ONE 4(5):e5539

66. Denger $\mathrm{S}$ et al (2001) ERalpha gene expression in human primary osteoblasts: evidence for the expression of two receptor proteins. Mol Endocrinol 15(12):2064-2077

67. Russell KS et al (2000) Human vascular endothelial cells contain membrane binding sites for estradiol, which mediate rapid intracellular signaling. Proc Natl Acad Sci U S A 97(11):5930-5935

68. Li L, Haynes MP, Bender JR (2003) Plasma membrane localization and function of the estrogen receptor alpha variant (ER46) in human endothelial cells. Proc Natl Acad Sci U S A 100(8):4807-4812

69. Klinge CM et al (2010) Estrogen receptor alpha 46 is reduced in tamoxifen resistant breast cancer cells and re-expression inhibits cell proliferation and estrogen receptor alpha 66-regulated target gene transcription. Mol Cell Endocrinol 323(2):268-276

70. Chantalat E et al (2016) The AF-1-deficient estrogen receptor ERalpha46 isoform is frequently expressed in human breast tumors. Breast Cancer Res 18(1):123

71. Wang $\mathrm{Z}$ et al (2005) Identification, cloning, and expression of human estrogen receptor-alpha36, a novel variant of human estrogen receptor-alpha66. Biochem Biophys Res Commun 336(4):1023-1027

72. Wang $Z$ et al (2006) A variant of estrogen receptor- $\{$ alpha $\}$, hER\{alpha\}36: transduction of estrogen- and antiestrogen-dependent membrane-initiated mitogenic signaling. Proc Natl Acad Sci U S A 103(24):9063-9068

73. Lee LM et al (2008) ER-alpha36, a novel variant of ER-alpha, is expressed in ER-positive and -negative human breast carcinomas. Anticancer Res 28(1B):479-483

74. Shi L et al (2009) Expression of ER-\{alpha\}36, a novel variant of estrogen receptor $\{$ alpha $\}$, and resistance to tamoxifen treatment in breast cancer. J Clin Oncol 27(21):3423-3429

75. Wang Q et al (2018) Tamoxifen enhances stemness and promotes metastasis of ERalpha36(+) breast cancer by upregulating ALDH1A1 in cancer cells. Cell Res 28(3):336-358

76. Thiebaut $\mathrm{C}$ et al (2020) The role of eralpha36 in development and tumor malignancy. Int J Mol Sci 21(11):4116

77. Brzozowski AM et al (1997) Molecular basis of agonism and antagonism in the oestrogen receptor. Nature 389(6652):753-758

78. Gruber CJ et al (2004) Anatomy of the estrogen response element. Trends Endocrinol Metab 15(2):73-78

79. Lin CY et al (2007) Whole-genome cartography of estrogen receptor alpha binding sites. PLoS Genet 3(6):e87

80. Safe S, Kim K (2008) Non-classical genomic estrogen receptor (ER)/specificity protein and ER/activating protein-1 signaling pathways. J Mol Endocrinol 41(5):263-275

81. Quaedackers ME et al (2007) Direct interaction between estrogen receptor alpha and NF-kappaB in the nucleus of living cells. Mol Cell Endocrinol 273(1-2):42-50

82. Stender JD et al (2010) Genome-wide analysis of estrogen receptor alpha DNA binding and tethering mechanisms identifies Runx 1 as a novel tethering factor in receptor-mediated transcriptional activation. Mol Cell Biol 30(16):3943-3955 
83. Stender JD et al (2011) The estrogen-regulated transcription factor PITX1 coordinates gene-specific regulation by estrogen receptor-alpha in breast cancer cells. Mol Endocrinol 25(10):1699-1709

84. Carroll JS et al (2006) Genome-wide analysis of estrogen receptor binding sites. Nat Genet 38(11):1289-1297

85. Fullwood MJ et al (2009) An oestrogen-receptor-alpha-bound human chromatin interactome. Nature 462(7269):58-64

86. Welboren WJ et al (2009) Genomic actions of estrogen receptor alpha: what are the targets and how are they regulated? Endocr Relat Cancer 16(4):1073-1089

87. Bourdeau V et al (2004) Genome-wide identification of highaffinity estrogen response elements in human and mouse. Mol Endocrinol 18(6):1411-1427

88. Li W et al (2013) Functional roles of enhancer RNAs for oestrogen-dependent transcriptional activation. Nature 498(7455):516-520

89. Palaniappan $\mathrm{M}$ et al (2019) The genomic landscape of estrogen receptor alpha binding sites in mouse mammary gland. PLoS ONE 14(8):e0220311

90. Ignar-Trowbridge DM et al (1995) Cross talk between peptide growth factor and estrogen receptor signaling systems. Environ Health Perspect 103(Suppl 7):35-38

91. Likhite VS et al (2006) Kinase-specific phosphorylation of the estrogen receptor changes receptor interactions with ligand, deoxyribonucleic acid, and coregulators associated with alterations in estrogen and tamoxifen activity. Mol Endocrinol 20(12):3120-3132

92. Marquez DC et al (2001) Epidermal growth factor receptor and tyrosine phosphorylation of estrogen receptor. Endocrine 16(2):73-81

93. Le Goff P et al (1994) Phosphorylation of the human estrogen receptor. Identification of hormone-regulated sites and examination of their influence on transcriptional activity. J Biol Chem 269(6):4458-4466

94. Lannigan DA (2003) Estrogen receptor phosphorylation. Steroids 68(1):1-9

95. Medunjanin S et al (2005) Glycogen synthase kinase-3 interacts with and phosphorylates estrogen receptor alpha and is involved in the regulation of receptor activity. J Biol Chem 280(38):33006-33014

96. Rogatsky I, Trowbridge JM, Garabedian MJ (1999) Potentiation of human estrogen receptor alpha transcriptional activation through phosphorylation of serines 104 and 106 by the cyclin A-CDK2 complex. J Biol Chem 274(32):22296-22302

97. Johnston SR (2010) New strategies in estrogen receptor-positive breast cancer. Clin Cancer Res 16(7):1979-1987

98. Hurtado A et al (2011) FOXA1 is a key determinant of estrogen receptor function and endocrine response. Nat Genet 43(1):27-33

99. Madureira PA et al (2006) The Forkhead box M1 protein regulates the transcription of the estrogen receptor alpha in breast cancer cells. J Biol Chem 281(35):25167-25176

100. Cirillo LA et al (2002) Opening of compacted chromatin by early developmental transcription factors HNF3 (FoxA) and GATA-4. Mol Cell 9(2):279-289

101. Magnani L, Eeckhoute J, Lupien M (2011) Pioneer factors: directing transcriptional regulators within the chromatin environment. Trends Genet 27(11):465-474

102. Eeckhoute J, Metivier R, Salbert G (2009) Defining specificity of transcription factor regulatory activities. J Cell Sci 122(Pt 22):4027-4034

103. Caizzi L et al (2014) Genome-wide activity of unliganded estrogen receptor-alpha in breast cancer cells. Proc Natl Acad Sci U S A 111(13):4892-4897
104. Marino M, Ascenzi P, Acconcia F (2006) S-palmitoylation modulates estrogen receptor alpha localization and functions. Steroids 71(4):298-303

105. Szego CM, Davis JS (1967) Adenosine 3',5'-monophosphate in rat uterus: acute elevation by estrogen. Proc Natl Acad Sci U S A 58(4):1711-1718

106. Pietras RJ, Szego CM (1977) Specific binding sites for oestrogen at the outer surfaces of isolated endometrial cells. Nature 265(5589):69-72

107. Levin BE et al (2011) Metabolic sensing and the brain: who, what, where, and how? Endocrinology 152(7):2552-2557

108. Razandi M et al (1999) Cell membrane and nuclear estrogen receptors (ERs) originate from a single transcript: studies of ERalpha and ERbeta expressed in Chinese hamster ovary cells. Mol Endocrinol 13(2):307-319

109. Razandi $\mathrm{M}$ et al (2003) Identification of a structural determinant necessary for the localization and function of estrogen receptor alpha at the plasma membrane. Mol Cell Biol 23(5):1633-1646

110. Lu Q et al (2004) Striatin assembles a membrane signaling complex necessary for rapid, nongenomic activation of endothelial NO synthase by estrogen receptor alpha. Proc Natl Acad Sci USA 101(49):17126-17131

111. Acconcia F et al (2004) S-palmitoylation modulates human estrogen receptor-alpha functions. Biochem Biophys Res Commun 316(3):878-883

112. Pedram A et al (2007) A conserved mechanism for steroid receptor translocation to the plasma membrane. J Biol Chem 282(31):22278-22288

113. Le Romancer M et al (2008) Regulation of estrogen rapid signaling through arginine methylation by PRMT1. Mol Cell 31(2):212-221

114. Adlanmerini $\mathrm{M}$ et al (2014) Mutation of the palmitoylation site of estrogen receptor alpha in vivo reveals tissue-specific roles for membrane versus nuclear actions. Proc Natl Acad Sci U S A 111(2):E283-E290

115. Pedram A et al (2014) Membrane-localized estrogen receptor alpha is required for normal organ development and function. Dev Cell 29(4):482-490

116. Adlanmerini M et al (2020) Mutation of arginine 264 on ERalpha (Estrogen Receptor Alpha) selectively abrogates the rapid signaling of estradiol in the endothelium without altering fertility. Arterioscler Thromb Vasc Biol 40(9):2143-2158

117. Bernelot Moens SJ et al (2012) Rapid estrogen receptor signaling is essential for the protective effects of estrogen against vascular injury. Circulation 126(16):1993-2004

118. Harrison DG (1997) Cellular and molecular mechanisms of endothelial cell dysfunction. J Clin Invest 100(9):2153-2157

119. Madak-Erdogan Z et al (2016) Design of pathway preferential estrogens that provide beneficial metabolic and vascular effects without stimulating reproductive tissues. Sci Signal 9(429):53

120. Madak-Erdogan $Z$ et al (2008) Nuclear and extranuclear pathway inputs in the regulation of global gene expression by estrogen receptors. Mol Endocrinol 22(9):2116-2127

121. Vicent GP et al (2006) Chromatin remodeling and control of cell proliferation by progestins via cross talk of progesterone receptor with the estrogen receptors and kinase signaling pathways. Ann N Y Acad Sci 1089:59-72

122. Copley SD (2014) An evolutionary perspective on protein moonlighting. Biochem Soc Trans 42(6):1684-1691

123. Jeffery CJ (1999) Moonlighting proteins. Trends Biochem Sci 24(1):8-11

124. Moumen $\mathrm{M}$ et al (2011) The mammary myoepithelial cell. Int J Dev Biol 55(7-9):763-771 
125. Stevenson AJ et al (2020) Multiscale imaging of basal cell dynamics in the functionally mature mammary gland. Proc Natl Acad Sci USA 117(43):26822-26832

126. Joshi PA, Di Grappa MA, Khokha R (2012) Active allies: hormones, stem cells and the niche in adult mammopoiesis. Trends Endocrinol Metab 23(6):299-309

127. Williams JM, Daniel CW (1983) Mammary ductal elongation: differentiation of myoepithelium and basal lamina during branching morphogenesis. Dev Biol 97(2):274-290

128. Mailleux AA et al (2007) BIM regulates apoptosis during mammary ductal morphogenesis, and its absence reveals alternative cell death mechanisms. Dev Cell 12(2):221-234

129. Scheele CL et al (2017) Identity and dynamics of mammary stem cells during branching morphogenesis. Nature 542(7641):313-317

130. Paine IS, Lewis MT (2017) The terminal end bud: the little engine that could. J Mammary Gland Biol Neoplasia 22(2):93-108

131. Brisken C (2013) Progesterone signalling in breast cancer: a neglected hormone coming into the limelight. Nat Rev Cancer 13(6):385-396

132. Need EF et al (2014) Hormonal regulation of the immune microenvironment in the mammary gland. J Mammary Gland Biol Neoplasia 19(2):229-239

133. Gimpl G, Fahrenholz F (2001) The oxytocin receptor system: structure, function, and regulation. Physiol Rev 81(2):629-683

134. Cheng $\mathrm{G}$ et al (2004) Estrogen receptors ER alpha and ER beta in proliferation in the rodent mammary gland. Proc Natl Acad Sci U S A 101(11):3739-3746

135. Vandenberg LN et al (2006) The mammary gland response to estradiol: monotonic at the cellular level, non-monotonic at the tissue-level of organization? J Steroid Biochem Mol Biol 101(4-5):263-274

136. Haslam SZ, Shyamala G (1979) Progesterone receptors in normal mammary glands of mice: characterization and relationship to development. Endocrinology 105(3):786-795

137. Leondires MP et al (2002) Estradiol stimulates expression of two human prolactin receptor isoforms with alternative exons-1 in T47D breast cancer cells. J Steroid Biochem Mol Biol 82(2-3):263-268

138. Cagnet $\mathrm{S}$ et al (2018) Oestrogen receptor alpha AF-1 and AF-2 domains have cell population-specific functions in the mammary epithelium. Nat Commun 9(1):4723

139. Shackleton $\mathrm{M}$ et al (2006) Generation of a functional mammary gland from a single stem cell. Nature 439(7072):84-88

140. Stingl J et al (2006) Purification and unique properties of mammary epithelial stem cells. Nature 439(7079):993-997

141. Sleeman KE et al (2007) Dissociation of estrogen receptor expression and in vivo stem cell activity in the mammary gland. J Cell Biol 176(1):19-26

142. Van Keymeulen A et al (2011) Distinct stem cells contribute to mammary gland development and maintenance. Nature 479(7372):189-193

143. Prater MD et al (2014) Mammary stem cells have myoepithelial cell properties. Nat Cell Biol 16(10):942-950

144. Rodilla V et al (2015) Luminal progenitors restrict their lineage potential during mammary gland development. PLoS Biol 13(2):1002069

145. Van Keymeulen A et al (2017) Lineage-restricted mammary stem cells sustain the development, homeostasis, and regeneration of the estrogen receptor positive lineage. Cell Rep 20(7):1525-1532

146. Lloyd-Lewis B et al (2017) Mammary stem cells: premise, properties, and perspectives. Trends Cell Biol 27(8):556-567

147. Oakes SR, Gallego-Ortega D, Ormandy CJ (2014) The mammary cellular hierarchy and breast cancer. Cell Mol Life Sci 71(22):4301-4324
148. Centonze A et al (2020) Heterotypic cell-cell communication regulates glandular stem cell multipotency. Nature 584(7822):608-613

149. Zeps $\mathrm{N}$ et al (1998) Estrogen receptor-negative epithelial cells in mouse mammary gland development and growth. Differentiation 62(5):221-226

150. Bernardo GM et al (2010) FOXA1 is an essential determinant of ERalpha expression and mammary ductal morphogenesis. Development 137(12):2045-2054

151. Giraddi RR et al (2015) Stem and progenitor cell division kinetics during postnatal mouse mammary gland development. Nat Commun 6:8487

152. Rajaram RD et al (2015) Progesterone and Wnt4 control mammary stem cells via myoepithelial crosstalk. EMBO J 34(5):641-652

153. Pedroza DA, Subramani R, Lakshmanaswamy R (2020) Classical and non-classical progesterone signaling in breast cancers. Cancers (Basel) 12(9):2440

154. Aupperlee MD et al (2005) Progesterone receptor isoforms A and B: temporal and spatial differences in expression during murine mammary gland development. Endocrinology 146(8):3577-3588

155. Mulac-Jericevic B et al (2003) Defective mammary gland morphogenesis in mice lacking the progesterone receptor B isoform. Proc Natl Acad Sci USA 100(17):9744-9749

156. Clarke RB et al (1997) Dissociation between steroid receptor expression and cell proliferation in the human breast. Cancer Res 57(22):4987-4991

157. Booth BW, Smith GH (2006) Estrogen receptor-alpha and progesterone receptor are expressed in label-retaining mammary epithelial cells that divide asymmetrically and retain their template DNA strands. Breast Cancer Res 8(4):R49

158. Oliver $\mathrm{CH}$ et al (2012) The Stat6-regulated KRAB domain zinc finger protein Zfp157 regulates the balance of lineages in mammary glands and compensates for loss of Gata-3. Genes Dev 26(10):1086-1097

159. Anderson E, Clarke RB (2004) Steroid receptors and cell cycle in normal mammary epithelium. J Mammary Gland Biol Neoplasia 9(1):3-13

160. Rosen JM (2003) Hormone receptor patterning plays a critical role in normal lobuloalveolar development and breast cancer progression. Breast Dis 18:3-9

161. Russo J et al (1999) Pattern of distribution of cells positive for estrogen receptor alpha and progesterone receptor in relation to proliferating cells in the mammary gland. Breast Cancer Res Treat 53(3):217-227

162. Bach K et al (2017) Differentiation dynamics of mammary epithelial cells revealed by single-cell RNA sequencing. Nat Commun 8(1):2128

163. Kendrick H et al (2008) Transcriptome analysis of mammary epithelial subpopulations identifies novel determinants of lineage commitment and cell fate. BMC Genomics 9:591

164. Shehata $\mathrm{M}$ et al (2012) Phenotypic and functional characterisation of the luminal cell hierarchy of the mammary gland. Breast Cancer Res 14(5):R134

165. Shehata $M$ et al (2014) The influence of tamoxifen on normal mouse mammary gland homeostasis. Breast Cancer Res 16(4):411

166. Chiche A et al (2019) p53 controls the plasticity of mammary luminal progenitor cells downstream of Met signaling. Breast Cancer Res 21(1):13

167. Bresson L et al (2018) Podoplanin regulates mammary stem cell function and tumorigenesis by potentiating Wnt/betacatenin signaling. Development 145(4)

168. Lim E et al (2009) Aberrant luminal progenitors as the candidate target population for basal tumor development in BRCA1 mutation carriers. Nat Med 15(8):907-913 
169. Bouras $\mathrm{T}$ et al (2008) Notch signaling regulates mammary stem cell function and luminal cell-fate commitment. Cell Stem Cell 3(4):429-441

170. Asselin-Labat ML, Lindeman GJ, Visvader JE (2011) Mammary stem cells and their regulation by steroid hormones. Expert Rev Endocrinol Metab 6(3):371-381

171. Regan JL et al (2012) c-Kit is required for growth and survival of the cells of origin of Brca1-mutation-associated breast cancer. Oncogene 31(7):869-883

172. Di-Cicco A et al (2015) Paracrine met signaling triggers epithelial-mesenchymal transition in mammary luminal progenitors, affecting their fate. Elife 4:e06104

173. Sleeman KE et al (2006) CD24 staining of mouse mammary gland cells defines luminal epithelial, myoepithelial/basal and non-epithelial cells. Breast Cancer Res 8(1):R7

174. De Silva D et al (2015) Transcriptome analysis of the hormonesensing cells in mammary epithelial reveals dynamic changes in early pregnancy. BMC Dev Biol 15:7

175. Wang $C$ et al (2017) Lineage-biased stem cells maintain Estrogen-receptor-positive and -negative mouse mammary luminal lineages. Cell Rep 18(12):2825-2835

176. Anderson LH et al (2011) Stem cell marker prominin-1 regulates branching morphogenesis, but not regenerative capacity, in the mammary gland. Dev Dyn 240(3):674-681

177. Pal B et al (2017) Construction of developmental lineage relationships in the mouse mammary gland by single-cell RNA profiling. Nat Commun 8(1):1627

178. Giraddi RR et al (2018) Single-cell transcriptomes distinguish stem cell state changes and lineage specification programs in early mammary gland development. Cell Rep 24(6):1653-1666e7

179. Pervolarakis $\mathrm{N}$ et al (2020) Integrated single-cell transcriptomics and chromatin accessibility analysis reveals regulators of mammary epithelial cell identity. Cell Rep 33(3):108273

180. Oakes SR et al (2008) The Ets transcription factor Elf5 specifies mammary alveolar cell fate. Genes Dev 22(5):581-586

181. Manavathi B, Samanthapudi VS, Gajulapalli VN (2014) Estrogen receptor coregulators and pioneer factors: the orchestrators of mammary gland cell fate and development. Front Cell Dev Biol $2: 34$

182. Kouros-Mehr H et al (2006) GATA-3 maintains the differentiation of the luminal cell fate in the mammary gland. Cell 127(5):1041-1055

183. Kouros-Mehr $\mathrm{H}$ et al (2008) GATA-3 and the regulation of the mammary luminal cell fate. Curr Opin Cell Biol 20(2):164-170

184. Asselin-Labat ML et al (2006) Steroid hormone receptor status of mouse mammary stem cells. J Natl Cancer Inst 98(14):1011-1014

185. Kunasegaran K et al (2014) Transcriptional repressor Tbx3 is required for the hormone-sensing cell lineage in mammary epithelium. PLoS ONE 9(10):e110191

186. Howlin $\mathrm{J}$ et al (2006) CITED1 homozygous null mice display aberrant pubertal mammary ductal morphogenesis. Oncogene 25(10): 1532-1542

187. Fata JE et al (2000) The osteoclast differentiation factor osteoprotegerin-ligand is essential for mammary gland development. Cell 103(1):41-50

188. Joshi PA et al (2010) Progesterone induces adult mammary stem cell expansion. Nature 465(7299):803-807

189. Asselin-Labat ML et al (2010) Control of mammary stem cell function by steroid hormone signalling. Nature 465(7299):798-802

190. Ciarloni L, Mallepell S, Brisken C (2007) Amphiregulin is an essential mediator of estrogen receptor alpha function in mammary gland development. Proc Natl Acad Sci USA 104(13):5455-5460
191. Kanaya N et al (2019) Single-cell RNA-sequencing analysis of estrogen- and endocrine-disrupting chemical-induced reorganization of mouse mammary gland. Commun Biol 2:406

192. Li CM et al (2020) Aging-associated alterations in mammary epithelia and stroma revealed by single-cell RNA sequencing. Cell Rep 33(13): 108566

193. Beleut $\mathrm{M}$ et al (2010) Two distinct mechanisms underlie progesterone-induced proliferation in the mammary gland. Proc Natl Acad Sci USA 107(7):2989-2994

194. Yalcin-Ozuysal O et al (2010) Antagonistic roles of Notch and p63 in controlling mammary epithelial cell fates. Cell Death Differ 17(10):1600-1612

195. Lilja AM et al (2018) Clonal analysis of Notch1-expressing cells reveals the existence of unipotent stem cells that retain longterm plasticity in the embryonic mammary gland. Nat Cell Biol 20(6):677-687

196. Rizzo P et al (2008) Cross-talk between notch and the estrogen receptor in breast cancer suggests novel therapeutic approaches. Cancer Res 68(13):5226-5235

197. Geng A et al (2020) A novel function of R-spondin1 in regulating estrogen receptor expression independent of Wnt/beta-catenin signaling. Elife 9:e56434

198. Mueller SO et al (2002) Mammary gland development in adult mice requires epithelial and stromal estrogen receptor alpha. Endocrinology 143(6):2357-2365

199. Dupont $\mathrm{S}$ et al (2000) Effect of single and compound knockouts of estrogen receptors alpha (ERalpha) and beta (ERbeta) on mouse reproductive phenotypes. Development 127(19):4277-4291

200. Pendaries $C$ et al (2002) The AF-1 activation-function of ERalpha may be dispensable to mediate the effect of estradiol on endothelial NO production in mice. Proc Natl Acad Sci USA 99(4):2205-2210

201. Feng Y et al (2007) Estrogen receptor-alpha expression in the mammary epithelium is required for ductal and alveolar morphogenesis in mice. Proc Natl Acad Sci USA 104(37):14718-14723

202. Matulka LA, Triplett AA, Wagner KU (2007) Parity-induced mammary epithelial cells are multipotent and express cell surface markers associated with stem cells. Dev Biol 303(1):29-44

203. Sternlicht MD et al (2005) Mammary ductal morphogenesis requires paracrine activation of stromal EGFR via ADAM17dependent shedding of epithelial amphiregulin. Development 132(17):3923-3933

204. McBryan J et al (2008) Amphiregulin: role in mammary gland development and breast cancer. J Mammary Gland Biol Neoplasia 13(2):159-169

205. Luetteke NC et al (1999) Targeted inactivation of the EGF and amphiregulin genes reveals distinct roles for EGF receptor ligands in mouse mammary gland development. Development 126(12):2739-2750

206. Hovey RC, Trott JF, Vonderhaar BK (2002) Establishing a framework for the functional mammary gland: from endocrinology to morphology. J Mammary Gland Biol Neoplasia 7(1):17-38

207. Arao $\mathrm{Y}$ et al (2011) Estrogen receptor alpha AF-2 mutation results in antagonist reversal and reveals tissue selective function of estrogen receptor modulators. Proc Natl Acad Sci U S A 108(36): 14986-14991

208. Billon-Gales A et al (2011) Activation function 2 (AF2) of estrogen receptor-alpha is required for the atheroprotective action of estradiol but not to accelerate endothelial healing. Proc Natl Acad Sci U S A 108(32):13311-13316

209. Ahlbory-Dieker DL et al (2009) DNA binding by estrogen receptor-alpha is essential for the transcriptional response to estrogen in the liver and the uterus. Mol Endocrinol 23(10):1544-1555

210. Jakacka $\mathrm{M}$ et al (2002) An estrogen receptor (ER)alpha deoxyribonucleic acid-binding domain knock-in mutation provides 
evidence for nonclassical ER pathway signaling in vivo. Mol Endocrinol 16(10):2188-2201

211. Sinkevicius KW et al (2008) An estrogen receptor-alpha knock-in mutation provides evidence of ligand-independent signaling and allows modulation of ligand-induced pathways in vivo. Endocrinology 149(6):2970-2979

212. Gagniac L et al (2020) Membrane expression of the estrogen receptor ERalpha is required for intercellular communications in the mammary epithelium. Development 147(5):dev182303

213. Mohammed $\mathrm{H}$ et al (2013) Endogenous purification reveals GREB1 as a key estrogen receptor regulatory factor. Cell Rep 3(2):342-349

214. Pedram A et al (2009) Developmental phenotype of a membrane only estrogen receptor alpha (MOER) mouse. J Biol Chem 284(6):3488-3495

215. Thiebaut $C$ et al (2017) Mammary epithelial cell phenotype disruption in vitro and in vivo through ERalpha36 overexpression. PLoS ONE 12(3):e0173931

216. Eeckhoute J et al (2006) A cell-type-specific transcriptional network required for estrogen regulation of cyclin D1 and cell cycle progression in breast cancer. Genes Dev 20(18):2513-2526

217. Badve $\mathrm{S}$ et al (2007) FOXA1 expression in breast cancer-correlation with luminal subtype A and survival. Clin Cancer Res 13(15 Pt 1):4415-4421

218. Thorat MA et al (2008) Forkhead box A1 expression in breast cancer is associated with luminal subtype and good prognosis. J Clin Pathol 61(3):327-332

219. Carroll JS et al (2005) Chromosome-wide mapping of estrogen receptor binding reveals long-range regulation requiring the forkhead protein FoxA1. Cell 122(1):33-43

220. Asselin-Labat ML et al (2007) Gata-3 is an essential regulator of mammary-gland morphogenesis and luminal-cell differentiation. Nat Cell Biol 9(2):201-209

221. Naylor MJ, Ormandy CJ (2007) Gata-3 and mammary cell fate. Breast Cancer Res 9(2):302

222. Kong SL et al (2011) Cellular reprogramming by the conjoint action of ERalpha, FOXA1, and GATA3 to a ligand-inducible growth state. Mol Syst Biol 7:526

223. Kouros-Mehr H, Werb Z (2006) Candidate regulators of mammary branching morphogenesis identified by genome-wide transcript analysis. Dev Dyn 235(12):3404-3412

224. Theodorou V et al (2013) GATA3 acts upstream of FOXA1 in mediating ESR1 binding by shaping enhancer accessibility. Genome Res 23(1):12-22

225. Carr JR et al (2012) FoxM1 regulates mammary luminal cell fate. Cell Rep 1(6):715-729

226. Kim MR et al (2020) TET2 directs mammary luminal cell differentiation and endocrine response. Nat Commun 11(1):4642

227. Xu J et al (1998) Partial hormone resistance in mice with disruption of the steroid receptor coactivator-1 (SRC-1) gene. Science 279(5358):1922-1925

228. Gehin $\mathrm{M}$ et al (2002) The function of TIF2/GRIP1 in mouse reproduction is distinct from those of SRC-1 and p/CIP. Mol Cell Biol 22(16):5923-5937

229. Mukherjee A et al (2006) Steroid receptor coactivator 2 is critical for progesterone-dependent uterine function and mammary morphogenesis in the mouse. Mol Cell Biol 26(17):6571-6583

230. Xu J et al (2000) The steroid receptor coactivator SRC-3 (p/CIP/ RAC3/AIB1/ACTR/TRAM-1) is required for normal growth, puberty, female reproductive function, and mammary gland development. Proc Natl Acad Sci USA 97(12):6379-6384

231. Han SJ et al (2006) Steroid receptor coactivator (SRC)-1 and SRC-3 differentially modulate tissue-specific activation functions of the progesterone receptor. Mol Endocrinol 20(1):45-55

232. Park $\mathrm{S}$ et al (2011) Repressor of estrogen receptor activity (REA) is essential for mammary gland morphogenesis and functional activities: studies in conditional knockout mice. Endocrinology 152(11):4336-4349

233. Nautiyal J et al (2013) The transcriptional co-factor RIP140 regulates mammary gland development by promoting the generation of key mitogenic signals. Development 140(5):1079-1089

234. Ruan W, Newman CB, Kleinberg DL (1992) Intact and aminoterminally shortened forms of insulin-like growth factor I induce mammary gland differentiation and development. Proc Natl Acad Sci USA 89(22):10872-10876

235. Kleinberg DL, Feldman M, Ruan W (2000) IGF-I: an essential factor in terminal end bud formation and ductal morphogenesis. J Mammary Gland Biol Neoplasia 5(1):7-17

236. Bonnette SG, Hadsell DL (2001) Targeted disruption of the IGF-I receptor gene decreases cellular proliferation in mammary terminal end buds. Endocrinology 142(11):4937-4945

237. Louvi A, Accili D, Efstratiadis A (1997) Growth-promoting interaction of IGF-II with the insulin receptor during mouse embryonic development. Dev Biol 189(1):33-48

238. Brisken $\mathrm{C}$ et al (2002) IGF-2 is a mediator of prolactin-induced morphogenesis in the breast. Dev Cell 3(6):877-887

239. Jones RA et al (2007) Transgenic overexpression of IGF-IR disrupts mammary ductal morphogenesis and induces tumor formation. Oncogene 26(11):1636-1644

240. Tian J et al (2012) Developmental stage determines estrogen receptor alpha expression and non-genomic mechanisms that control IGF-1 signaling and mammary proliferation in mice. $\mathrm{J}$ Clin Invest 122(1):192-204

241. Zhang M, Lee AV, Rosen JM (2017) The cellular origin and evolution of breast cancer. Cold Spring Harb Perspect Med 7(3):a027128

242. Minussi DC et al (2021) Breast tumours maintain a reservoir of subclonal diversity during expansion. Nature 592(7853):302-308

243. Jackson HW et al (2020) The single-cell pathology landscape of breast cancer. Nature 578(7796):615-620

244. Polyak K, Vogt PK (2012) Progress in breast cancer research. Proc Natl Acad Sci USA 109(8):2715-2717

245. Murphy CG, Dickler MN (2016) Endocrine resistance in hormone-responsive breast cancer: mechanisms and therapeutic strategies. Endocr Relat Cancer 23(8):R337-R352

246. Beatson $G$ (1896) On treatment of inoperable cases of carcinoma of the mamma: suggestions for a new method of treatment with illustrative cases. Lancet 11:104-107

247. Dall GV, Britt KL (2017) Estrogen effects on the mammary gland in early and late life and breast cancer risk. Front Oncol 7:110

248. Morch LS, Hannaford PC, Lidegaard O (2018) Contemporary hormonal contraception and the risk of breast cancer. N Engl J Med 378(13):1265-1266

249. Dall G, Risbridger G, Britt K (2017) Mammary stem cells and parity-induced breast cancer protection- new insights. J Steroid Biochem Mol Biol 170:54-60

250. Unar-Munguia $M$ et al (2017) Breastfeeding mode and risk of breast cancer: a dose-response meta-analysis. J Hum Lact 33(2):422-434

251. Peachman RR (2018) Weighing the risks and benefits of hormonal contraception. JAMA 319(11):1083-1084

252. Anderson GL et al (2006) Prior hormone therapy and breast cancer risk in the Women's Health Initiative randomized trial of estrogen plus progestin. Maturitas 55(2):103-115

253. Anderson GL et al (2004) Effects of conjugated equine estrogen in postmenopausal women with hysterectomy: the women's health initiative randomized controlled trial. JAMA 291(14):1701-1712

254. Vinogradova Y, Coupland C, Hippisley-Cox J (2020) Use of hormone replacement therapy and risk of breast cancer: nested case-control studies using the QResearch and CPRD databases. BMJ 371:m3873 
255. Kutasovic JR et al (2020) Morphologic and genomic heterogeneity in the evolution and progression of breast cancer. Cancers (Basel) 12(4):848

256. Gu G, Fuqua SA (2016) ESR1 mutations in breast cancer: proof-of-concept challenges clinical action. Clin Cancer Res 22(5):1034-1036

257. Herynk MH, Fuqua SA (2004) Estrogen receptor mutations in human disease. Endocr Rev 25(6):869-898

258. Angus L et al (2017) ESR1 mutations: Moving towards guiding treatment decision-making in metastatic breast cancer patients. Cancer Treat Rev 52:33-40

259. Pejerrey SM et al (2018) The impact of esr1 mutations on the treatment of metastatic breast cancer. Horm Cancer 9(4):215-228

260. Katzenellenbogen JA et al (2018) Structural underpinnings of oestrogen receptor mutations in endocrine therapy resistance. Nat Rev Cancer 18(6):377-388

261. Jeselsohn R et al (2015) ESR1 mutations-a mechanism for acquired endocrine resistance in breast cancer. Nat Rev Clin Oncol 12(10):573-583

262. Spoerke JM et al (2016) Heterogeneity and clinical significance of ESR1 mutations in ER-positive metastatic breast cancer patients receiving fulvestrant. Nat Commun 7:11579

263. Castoria G et al (2012) Tyrosine phosphorylation of estradiol receptor by Src regulates its hormone-dependent nuclear export and cell cycle progression in breast cancer cells. Oncogene 31(46):4868-4877

264. Migliaccio A et al (2000) Steroid-induced androgen receptoroestradiol receptor beta-Src complex triggers prostate cancer cell proliferation. EMBO J 19(20):5406-5417

265. Arnold SF et al (1997) Estradiol-binding mechanism and binding capacity of the human estrogen receptor is regulated by tyrosine phosphorylation. Mol Endocrinol 11(1):48-53

266. Arnold SF et al (1995) Phosphorylation of the human estrogen receptor on tyrosine 537 in vivo and by src family tyrosine kinases in vitro. Mol Endocrinol 9(1):24-33

267. Arnold SF, Vorojeikina DP, Notides AC (1995) Phosphorylation of tyrosine 537 on the human estrogen receptor is required for binding to an estrogen response element. J Biol Chem 270(50):30205-30212

268. Jeselsohn R et al (2018) Allele-specific chromatin recruitment and therapeutic vulnerabilities of ESR1 activating mutations. Cancer Cell 33(2):173-186e5

269. Fanning SW et al (2016) Estrogen receptor alpha somatic mutations Y537S and D538G confer breast cancer endocrine resistance by stabilizing the activating function- 2 binding conformation. Elife 5:e12792

270. Gu G et al (2020) Hormonal modulation of ESR1 mutant metastasis. Oncogene 40(5):997-1011

271. Toy W et al (2013) ESR1 ligand-binding domain mutations in hormone-resistant breast cancer. Nat Genet 45(12):1439-1445

272. Jeselsohn $\mathrm{R}$ et al (2017) The evolving role of the estrogen receptor mutations in endocrine therapy-resistant breast cancer. Curr Oncol Rep 19(5):35

273. Hamadeh IS et al (2018) Personalizing aromatase inhibitor therapy in patients with breast cancer. Cancer Treat Rev 70:47-55

274. Jeselsohn R et al (2014) Emergence of constitutively active estrogen receptor-alpha mutations in pretreated advanced estrogen receptor-positive breast cancer. Clin Cancer Res 20(7):1757-1767

275. Robinson DR et al (2013) Activating ESR1 mutations in hormone-resistant metastatic breast cancer. Nat Genet 45(12):1446-1451

276. Clusan L et al (2021) A closer look at estrogen receptor mutations in breast cancer and their implications for estrogen and antiestrogen responses. Int J Mol Sci 22(2):756
277. Lei JT, Gou X, Ellis MJ (2018) ESR1 fusions drive endocrine therapy resistance and metastasis in breast cancer. Mol Cell Oncol 5(6):e1526005

278. Garcia-Martinez L et al (2021) Epigenetic mechanisms in breast cancer therapy and resistance. Nat Commun 12(1):1786

279. Ozdemir BC, Sflomos G, Brisken C (2018) The challenges of modeling hormone receptor-positive breast cancer in mice. Endocr Relat Cancer 25(5):R319-R330

280. Kersten K et al (2017) Genetically engineered mouse models in oncology research and cancer medicine. EMBO Mol Med 9(2):137-153

281. Fluck MM, Schaffhausen BS (2009) Lessons in signaling and tumorigenesis from polyomavirus middle $\mathrm{T}$ antigen. Microbiol Mol Biol Rev 73(3):542-563

282. Attalla $\mathrm{S}$ et al (2020) Insights from transgenic mouse models of PyMT-induced breast cancer: recapitulating human breast cancer progression in vivo. Oncogene 24:1-7

283. Frech MS et al (2005) Deregulated estrogen receptor alpha expression in mammary epithelial cells of transgenic mice results in the development of ductal carcinoma in situ. Cancer Res 65(3):681-685

284. Herynk $\mathrm{MH}$ et al (2009) Accelerated mammary maturation and differentiation, and delayed MMTVneu-induced tumorigenesis of K303R mutant ERalpha transgenic mice. Oncogene 28(36):3177-3187

285. Chan SR et al (2012) STAT1-deficient mice spontaneously develop estrogen receptor alpha-positive luminal mammary carcinomas. Breast Cancer Res 14(1):R16

286. Ando $\mathrm{S}$ et al (2017) Conditional expression of Ki-Ras(G12V) in the mammary epithelium of transgenic mice induces estrogen receptor alpha (ERalpha)-positive adenocarcinoma. Oncogene 36(46):6420-6431

287. Koren $\mathrm{S}$ et al (2015) PIK3CA(H1047R) induces multipotency and multi-lineage mammary tumours. Nature 525(7567):114-118

288. Van Keymeulen A et al (2015) Reactivation of multipotency by oncogenic PIK3CA induces breast tumour heterogeneity. Nature 525(7567):119-123

289. Marangoni E et al (2007) A new model of patient tumor-derived breast cancer xenografts for preclinical assays. Clin Cancer Res 13(13):3989-3998

290. Gao H et al (2015) High-throughput screening using patientderived tumor xenografts to predict clinical trial drug response. Nat Med 21(11):1318-1325

291. Sflomos G et al (2016) A preclinical model for ERalpha-positive breast cancer points to the epithelial microenvironment as determinant of luminal phenotype and hormone response. Cancer Cell 29(3):407-422

292. Fiche $\mathrm{M}$ et al (2019) Intraductal patient-derived xenografts of estrogen receptor alpha-positive breast cancer recapitulate the histopathological spectrum and metastatic potential of human lesions. J Pathol 247(3):287-292

293. Sflomos G et al (2021) Intraductal xenografts show lobular carcinoma cells rely on their own extracellular matrix and LOXL1. EMBO Mol Med 13(3):e13180

294. Dawson CA et al (2020) Tissue-resident ductal macrophages survey the mammary epithelium and facilitate tissue remodelling. Nat Cell Biol 22(5):546-558

Publisher's Note Springer Nature remains neutral with regard to jurisdictional claims in published maps and institutional affiliations. 